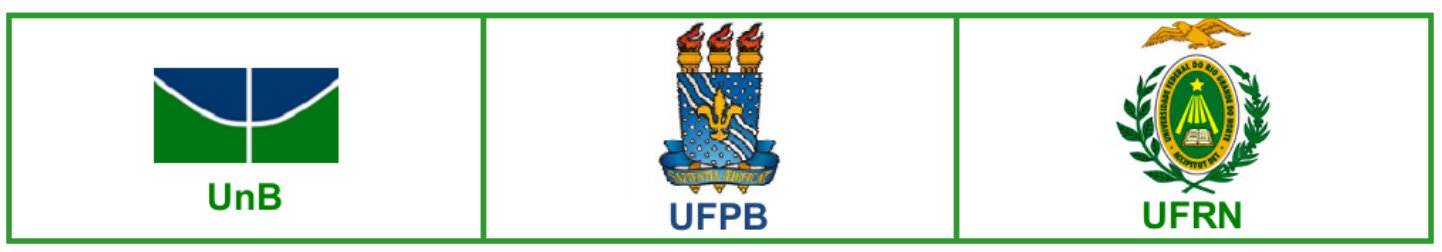

UNIVERSIDADE DE BRASÍLIA - UnB

UNIVERSIDADE FEDERAL DA PARAÍBA - UFPB

UNIVERSIDADE FEDERAL DO RIO GRANDE DO NORTE - UFRN

Programa Multiinstitucional e Inter-regional de Pós-graduação em Ciências

Contábeis

Marcelo Daniel Araujo Ermel

Controle acionário, remuneração de executivos e desempenho empresarial: evidências para o mercado brasileiro 
MARCELO DANIEL ARAUJO ERMEL

Controle acionário, remuneração de executivos e desempenho empresarial: evidências para o mercado brasileiro

Dissertação apresentada ao Programa Multiinstitucional e Inter-regional de Pós-graduação em Ciências Contábeis da Universidade de Brasília, Universidade Federal da Paraíba e Universidade Federal do Rio Grande do Norte, como requisito à obtenção do título de Mestre em Ciências Contábeis.

Linha de pesquisa: Governança corporativa e remuneração de executivos. 
Ficha catalográfica 


\section{CONTROLE ACIONÁRIO, REMUNERAÇÃO DE EXECUTIVOS E DESEMPENHO EMPRESARIAL: EVIDÊNCIAS PARA O MERCADO BRASILEIRO}

Dissertação apresentada como requisito parcial à obtenção do título de Mestre em Ciências Contábeis do Programa Multiinstitucional e Inter-regional de Pós-graduação em Ciências Contábeis da Universidade de Brasília, Universidade Federal da Paraíba e Universidade Federal do Rio Grande do Norte.

Data da aprovação:

BANCA EXAMINADORA:

Paulo Aguiar do Monte

Orientador - UnB/UFPB/UFRN

Adilson de Lima Tavares

Membro interno - UnB/UFPB/UFRN

Raquel Menezes Bezerra Sampaio

Membro externo - PPGA/UFRN 
Dedico aos meus pais, José Irineu Ermel e Regia Maria Guedes de Araujo, que me educaram com amor, me ensinaram o significado de caráter e transmitiram a razão do esforço. 
"Melhor morrer de pé do que viver de joelhos."

Emiliano Zapata 


\section{AGRADECIMENTOS}

Novamente agradeço a minha família, minha mãe que novamente torceu por mim, se preocupou por mim, chorou por mim, sorriu por mim. A minha irmã que me cobrou, me apoiou, me alertou, me orientou e sempre será um modelo de esforço e perseverança.

A todos os professores do programa que conheci nessa jornada, que me apoiaram e ajudaram quando necessitei. Agradeço especialmente a Professora Aneide Oliveira, figura única na vida acadêmica e pessoal, sua simplicidade, disposição e entrega a academia me servem de inspiração. Ao Professor Anderson Mol, menos formal, você é o cara. E ao meu orientador, Professor Paulo Aguiar, agradeço os ensinamentos.

Aos meus amigos e amigas, próximas ou distantes devido apenas pelo momento da vida, Andrew Mackenzie, Leonardo Oliveira, Victor França, Leandro Medeiros, Alinio Maciel, Guilherme Souza, Rafael Machado, Daniel Lopes, Ivan Hagi, , Adson Pereira, Airton Costa, Pedro Godeiro, Thales Jorge, Raphael Canuto, Felipe Assman, Astrid Lima, Clarissa Amaral, Rebeca Sabino, Rafaela Raissa, Bibiana Gouvêa, Alice Rosa, Louize Freire, Karol Fidelis, Sara Brito, Giordano Havel, Raimundo Marciano, Nyalle Matos, Gilberto Magalhães, Tarso Rocha, Jéssica de Abiahy. Se esqueci de alguém por favor não leve a mal, minha memória não é das melhores.

E por último não por preferência, e sim por necessitar novamente de um parágrafo para si, agradeço ao meu pai, quanto mais o tempo passa, mais eu percebo a raridade que são pessoas honestas, que se o mundo fosse feito de pessoas como você, que media as consequências de suas ações em relações ao próximo, seria um lugar muito melhor para se viver. Um homem que muito mais que vida, me deu caráter, profissão, educação e muito mais, que a saudade diária e constante seja transformada em força para seguir em frente... 


\section{RESUMO}

A remuneração de executivos atrai constante interesse da academia e do mercado. A teoria argumenta que a remuneração dos gestores deve estar atrelada ao desempenho empresarial para mitigar os custos de agências e evitar perdas a riqueza do acionista. Em 2009 a Comissão de Valores Mobiliários tornou obrigatória a divulgação da remuneração da diretoria. Essa dissertação buscou examinar como o tipo de controlador afeta a relação remuneração da diretoria nas empresas brasileiras no período de 2010 a 2013. Primeiramente, a análise demonstrou que o controle no Brasil ainda é majoritariamente exercido por firmas familiares, sendo $57 \%$ da amostra desse estudo, e que o capital também é concentrado, sendo em média $65 \%$ do capital detido pelos 5 maiores acionistas. Para atingir o objetivo desse trabalho, utilizou-se a metodologia de regressão com dados em painel. Os resultados indicaram que: 1. As empresas de controle familiar remuneram seus gestores com um valor menor, quando comparadas a empresas com os outros tipos de controle; 2 . Não foi possível fazer inferência acerca da influência do controlador nas empresas institucionais; 3. As empresas sem controlador remuneram o seu gestor com um valor maior de remuneração, quando comparado com as outras empresas da amostra; 4. As empresas de controle governamental, remuneram com um valor inferior em relação às outras empresas da amostra. Por fim, quanto ao desempenho, em nenhuma das equações o ROA foi significativo, demonstrando fracos mecanismos de remuneração ou capacidade do gestor em determinar sua compensação.

Palavras-chave: Controle acionário; Remuneração de executivos; Governança Corporativa 


\begin{abstract}
The executive compensation attracts constant interest of academy and the market. The theory argues that the manager's remuneration must be linked to business performance to mitigate agency costs and avoid losses shareholder wealth. In 2009 the Brazilian Commission of Securities and Exchange made it mandatory disclosure of the remuneration of the CEO. This paper aims to examine how the Ownership and Control affects the relative remuneration of Brazilian CEO's during the period of 2010 to 2013. First, the analysis showed that the control in Brazil is still largely exercised by families, they are $57 \%$ of the sample, and that the capital is also concentrated, averaging $65 \%$ of capital is held by five major shareholders. To achieve the objective of this study, we used the regression methodology with panel data. The results indicated that: 1 . The family-controlled companies remunerate their managers with a lower value, as compared to companies with other types of control; 2. It was not possible to make inferences about the influence of the controller in the institutional business; 3 . Companies without controller remunerate your manager with a higher amount of compensation when compared with other companies in the sample; 4 . The governmentcontrolled companies, remunerate with a lower value in relation to other companies in the sample. Finally, about performance, in any equations ROA was significant, demonstrating weak compensation mechanisms or manager's ability to determine their compensation.
\end{abstract}

Key-Words: Ownership-Control; Pay-Performance; Corporate Governance 


\section{LISTA DE SIGLAS}

CVM Comissão de Valores Mobiliários

BM\&FBOVESPA Bolsa de mercados Futuros e Bolsa de Valores de São Paulo

CEO

ROA

Chief Executive Officer (Diretor Presidente)

ROE

Retorno sobre Ativo

ROS

Retorno sobre Patrimônio Liquido

Retorno sobre Vendas 


\section{LISTA DE QUADROS E TABELAS}

Quadro 1 - Resumo dos principais estudos empíricos acerca de compensação de 24 executivos

Quadro 2 - Resumo das variáveis independentes utilizadas, e seus respectivos 29 sinais esperados, na estimação dos modelos de determinação da remuneração da diretoria executiva Tabela 1 - Estatística descritiva da amostra de empresas da BM\&FBOVESPA. 32 2010-2013

Tabela 2 - Remuneração (em R\$) das empresas de controle familiar. 2010 a 201333

Tabela 3 - Remuneração (em R\$) das empresas de controle institucional. 2010 a 33 2013

Tabela 4 - Remuneração (em R\$) das empresas de ausência de controle. 2010 a 34 2013

Tabela 5 - Remuneração (em R\$) das empresas de controle governamental. 201034 a 2013

Tabela 6 - Resultado do Teste T-Student para Diferença de Médias entre as 35 remunerações dos diferentes tipos de controle. 2010-2013

Tabela 7 - Resultado das estimações do modelo 1 que tem o objetivo de verificar 36 os determinantes da remuneração de acordo com o tipo de controlador. 2010-2013 Tabela 8 - Resultado das estimações do modelo 2 para verificar as diferenças 38 entre os controladores na sua influência sob a remuneração dos executivos. 20102013

Tabela 9 - Resultado da estimação do teste de robustez. 2010-2013 
Sumário

1 INTRODUÇÃO

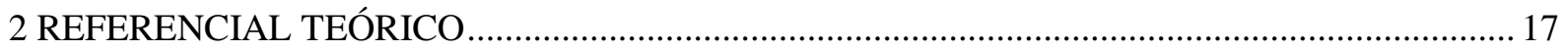

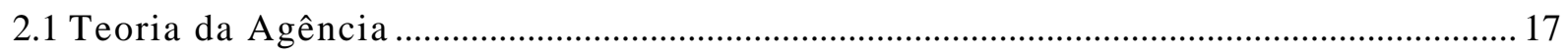

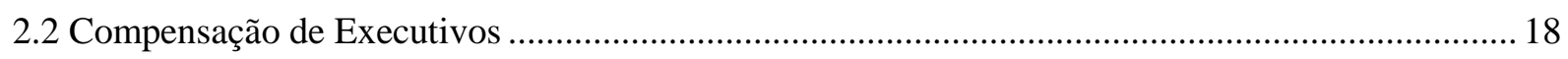

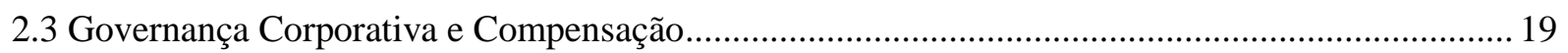

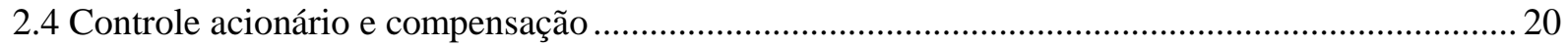

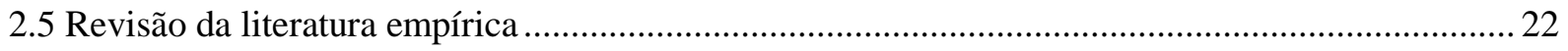

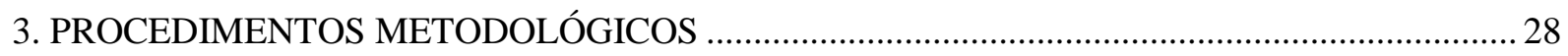

3.1 Os determinantes da remuneração e a influência do tipo de controle ............................................ 28

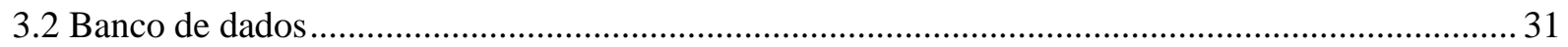

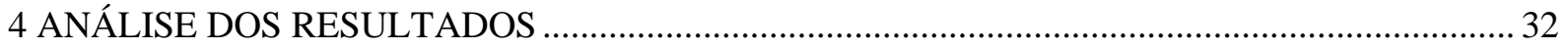

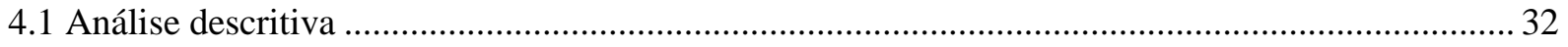

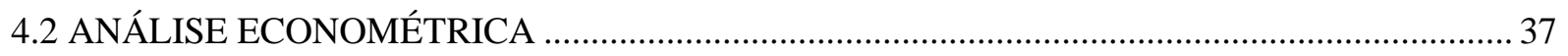

4.2.1 Testes de especificação do modelo de dados em painel .......................................................... 37

4.2.2 Resultados das estimações dos modelos de dados em painel .....................................................37

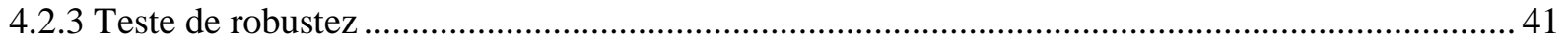

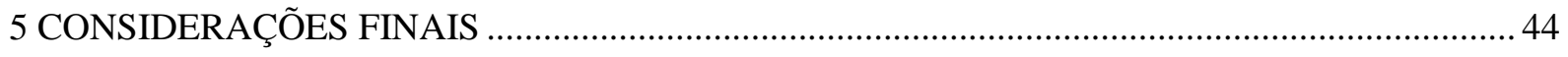

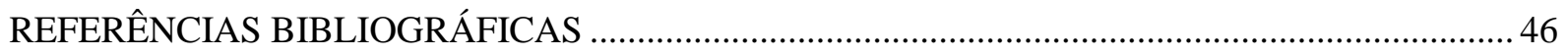




\section{INTRODUÇÃO}

A dissociação entre propriedade e controle tem sido objeto de estudos e preocupações constantes por parte dos profissionais, da imprensa e da academia (JENSEN; MURPHY, 2011; JENSEN et al., 2004; BEBCHUK; FRIED, 2005). Nessa relação o responsável por tomar as decisões que direcionam a instituição não é o proprietário, e sim, muitas vezes, apenas o seu gestor, que supostamente age no melhor interesse do seu contratante.

O primeiro compêndio feito na literatura acerca dessa situação foi elaborado por Jensen e Meckling (1976), que elencaram situações onde existe a possibilidade da entidade perder valor devido ao administrador agir em benefício e maximização de sua utilidade. Tal iniciativa gera situações em que a maximização de sua riqueza conflitará com a do acionista.

É nesse contexto que surgem os chamados “custos de agência”, que são os custos incorridos para certificar o proprietário de que o gestor não atue contra os seus interesses. Uma das iniciativas encontradas para mitigar os custos de agência e alinhar os interesses de acionistas e administradores é atrelar a remuneração dos gestores, ou uma parte dela, ao seu desempenho (JENSEN; MUPRHY, 1990; JENSEN et al., 2004; JENSEN; MURPHY, 2011).

Esse modelo de conflito de agência é pautado na arquitetura de controle e capital de firmas predominantes nos países anglo-saxões, onde o capital é disperso, assim, a propriedade da companhia não é simplesmente associada a um indivíduo. Em outros países, especialmente no continente europeu, as firmas são de propriedade familiar ou de seus herdeiros, com capital altamente concentrado (BARONTINI; BOZZI, 2011).

No modelo anglo-saxão, a remuneração do gestor é utilizada como uma forma de alinhar os interesses entre o gestor e os vários acionistas. Nos países não anglosaxões, quem indica o gestor e decide a remuneração é o acionista controlador. Dessa forma a remuneração pode ser usada para favorecer somente os interesses do acionista majoritário em detrimento dos interesses dos acionistas minoritários (BEBCHUK et al., 2001; MORCK; YEUNG, 2003).

No Brasil, o maior acionista detêm, em média, 50\% do capital total da empresa e 59\% do capital votante, evidenciando a alta concentração acionária (PINTO; LEAL, 2013). Essa alta concentração é comum nos países em desenvolvimento, enquanto em países desenvolvidos como Estados Unidos e Inglaterra, o capital médio detido pelo 
maior acionista é raramente maior que 20\% (CAO et al., 2011; BARONTINI; BOZZI, 2011).

Uma variável importante nessa relação entre remuneração e controle, é o tipo de controlador da empresa (familiar, institucional, governamental ou ausência de controlador). Na literatura acadêmica, dentro das firmas familiares, a remuneração do executivo deve ser atrelada ao desempenho da firma para conservar o nome da família e seu patrimônio, ou usada como forma de tunneling ${ }^{1}$ para expropriar riqueza do acionista minoritário. Para o primeiro caso, espera-se uma relação positiva entre remuneração e desempenho, enquanto que para o segundo caso não se espera uma relação significativa entre o desempenho e remuneração (DYER; WHETTEN, 2006; COHEN; LAUTERBACH, 2008; BARONTINI; BOZZI, 2011). Barontini e Bozzi (2011) constataram relação negativa entre desempenho e remuneração, para as firmas de controle familiar.

Já quando o controlador é institucional, espera-se uma relação positiva entre remuneração e desempenho, pois o investidor institucional terá a sua disposição, profissionais para fiscalizar e instituir planos de remuneração eficientes (EISENHARDT, 1989; DAVID; KOCHHAR, 1996; KHAN et al. 2005; HAID; YORTUGLU, 2006). CAO et al. (2011) encontraram uma maior sensibilidade na relação remuneração e desempenho, além de um maior uso de remuneração variável quando o seu controlador era institucional, investigando o mercado chinês.

Diante disso, chega-se a seguinte questão de pesquisa: No Brasil, como o tipo de controlador influência na remuneração dos executivos?

Esse estudo se justifica no fato de que a remuneração de executivos tem sido um tema recorrente na academia e no mercado, porém, grande parte da literatura trata apenas da relação entre remuneração e desempenho, dentro do desenho anglo-saxão de controle (DEVERS et al., 2007).

Poucos são os estudos que relacionam o tipo de controle a remuneração e desempenho da firma, especialmente em ambientes de alta concentração de capital e diferentes tipos de controladores (BARONTINI; BOZZI, 2011). Ademais, existe um número limitado de estudos nesse tema em mercados em desenvolvimento (CAO et al., 2011). Ainda, esse estudo se diferencia do estudo nacional anteriormente realizado por Pinto e Leal (2013), pois, esse teve como objetivo verificar o impacto na remuneração

${ }^{1}$ Utilizar ou transferir ativos e lucros da firma somente em beneficio do controlador. 
da diretoria no caso de existir relações familiares dentro do conselho de administração, ou, entre conselho e diretoria, analisando uma amostra de 315 companhias de capital aberto dentro da BM\&FBOVESPA no período de 2009 a 2010.

Assim, esta dissertação busca contribuir para a literatura acadêmica tendo como foco o tipo de controlador e sua relação entre remuneração e desempenho para o mercado brasileiro. Neste contexto, as características do Brasil, que possui um mercado de capitais em desenvolvimento haja vista o elevado número de empresas que abriram seu capital a partir de 2004. No período entre 2004 e 2012, cerca de 141 empresas iniciaram a negociação de ações na Bolsa de Mercados Futuros e Bolsa de Valores de São Paulo (BM\&FBOVESPA).

Esse grande número de ofertas primárias de ações trouxe uma mudança para a arquitetura de controle das empresas abertas, emergindo um número maior de empresas não-familiares (PINTO; LEAL, 2013). Ainda, a partir de 2009, por meio da instrução $n^{0}$ 480, a Comissão de Valores Mobiliários (CVM) passou a obrigar as empresas a detalhar seus planos de remuneração. Esta mudança na obrigatoriedade da divulgação das remunerações permite que se possa investigar a existência de relação entre remuneração e desempenho de forma mais clara.

Assim, esta pesquisa busca chamar a atenção para o tema de remuneração e tipo de controlador (familiar, institucional, ausência de controle e governamental), além de contribuir para a literatura ao explorar uma lacuna no assunto para o Brasil.

Com isso, o objetivo geral deste trabalho é investigar como os diferentes tipos de controlador influenciam na remuneração de executivos, no mercado brasileiro de capitais no período 2010-2013. Os objetivos específicos desse trabalho são analisar o perfil de controlador das empresas listadas na BM\&FBOVESPA e comparar seu impacto na remuneração dos gestores.

O primeiro objetivo específico será estabelecer e analisar o perfil do controlador das empresas listadas na BM\&FBOVESPA, ao passo de classifica-los nos seguintes grupos: Familiar, Institucional, Ausência de controlador e Governamental. Em seguida o segundo objetivo específico trata da análise do tipo de controlador e seu impacto na remuneração.

Além desta introdução, esta dissertação está dividida em mais quatro capítulos. O segundo capítulo refere-se à revisão da literatura, em que são revistos os estudos e conceitos da Teoria da Agência, compensação de executivos e controle acionário. O 
terceiro capítulo expõe a metodologia utilizada na pesquisa. O quarto capítulo contêm a análise dos resultados e por fim, o último destina-se as considerações finais. 


\section{REFERENCIAL TEÓRICO}

\subsection{Teoria da Agência}

O problema de agência na economia moderna pode ser dividido entre três partes: 1. O agente que administra o dia a dia da empresa; 2. O controlador que possui o direito de decidir acerca da estratégia e políticas da empresa, e; 3. O acionista que detém propriedade da empresa, mas não participa nem do cotidiano da entidade nem do controle da mesma.

Dentro do conflito de agência, considera-se que o Agente, gestor da entidade, e o Principal, proprietário da entidade, são maximizadores de utilidade. Neste processo há sempre a possibilidade do Agente agir em seu benefício em detrimento do benefício do Principal (ROSS, 1973). Diante disto, o Principal incorre em custos de monitoração para se certificar de que o agente está agindo de acordo com seus interesses, como por exemplo: implantações de conselho fiscal e conselho de administração, e o Agente incorre em custos de ligação para certificar o principal de que está cumprindo suas funções de forma correta, como auditoria das demonstrações contábeis. (JENSEN; MECKLING, 1976).

O puro problema de agência decorrente dos problemas da separação entre propriedade e controle, expostos por Berle e Means (1932), são moldados no modelo anglo-saxão de corporações, com um capital disperso entre os acionistas, onde a organização é gerenciada pelo seu administrador, que possui pouco ou nenhum capital da entidade (LA PORTA et al., 1999; BARONTINI; BOZZI, 2011).

Diante disso, para mitigar os custos de agência, propôs-se que contratos de remuneração dos gestores, ligados ao desempenho da entidade, seria uma alternativa inteligente para alinhar os interesses entre os Proprietários e o Agente (MURPHY, 1999). Caso o Agente fosse possuidor da totalidade das ações da firma, suas decisões teriam o objetivo de maximizar o valor da empresa. Porém, como geralmente o Agente possui pouca ou nenhuma ação, a maximização de sua utilidade passa por iniciativas gerenciais diferentes dos acionistas. (JENSEN; MURPHY, 2011).

Ainda, devido à propriedade dispersa, muitos dos acionistas não possuem o incentivo suficiente para fiscalizar o gestor. Dessa forma, o gestor detém influência significante sobre a determinação de sua remuneração, incentivando o surgimento de um custo de agência adicional, a própria remuneração. (BEBCHUK; FRIED, 2005). 
Outra forma de conflito de agência se dá no desenho de controle e propriedade em países não anglo-saxões, onde o controle é majoritariamente de famílias, e, ao contrário de um capital disperso, este encontra-se concentrado em um ou poucos acionistas. (BARONTINI; BOZZI, 2011). Assim, a remuneração do executivo é determinada pelo acionista majoritário, podendo esta ser uma forma de expropriação dos acionistas minoritários, pois o majoritário poderá atrelar a remuneração do gestor apenas ao que for de seu interesse, mesmo que alguma das vezes vá de encontro ao interesse dos acionistas minoritários (MORCK; YEUNG, 2003).

Portanto, o problema de agência muitas vezes não se observa entre os investidores e os administradores, e sim, entre os acionistas minoritários e o controlador (SHLEIFER; VISHNY, 1997).

\subsection{Compensação de Executivos}

A compensação de executivos pode atenuar o conflito de agência, uma vez que induz o comportamento do Agente em favor do interesse do acionista, ao incentiva-lo a atingir performances diretamente ligadas à medida que representem a riqueza do acionista (MURPHY, 1999). Segundo Aggarwal e Samwick (1999), a remuneração de executivos é o mecanismo de alinhamento de interesses mais forte dentro das corporações.

Dessa forma, para atenuar este conflito, faz-se necessário mais do que uma remuneração fixa, devido ao fato de que o gestor pode não se sentir motivado a exercer a sua função e obter o máximo de valor, sendo considerada a remuneração fixa uma posição de conforto.

Para Murphy (1999), a remuneração recebida pode ter caráter fixo ou variável, sendo a parcela fixa importante para recompensar administradores que possuem aversão ao risco e estabelecer um mínimo de remuneração atrativa para o gestor, além de ser um indicador a ser utilizado para definição da parcela variável. A importância da remuneração variável está no contexto de incentivar o administrador a maximizar o resultado da empresa, à medida que uma parcela de remuneração depende do desempenho da firma.

Atrelar a remuneração do Agente à riqueza do acionista a partir de medidas de desempenho incorre nos seguintes problemas: ao utilizar de medidas de desempenho contábeis para determinar a remuneração dos executivos, o gestor pode usar de certa 
discricionariedade para manipular o indicador a seu favor e determinar sua própria remuneração (ROSEN, 1993). Como solução, foi proposto a utilização de medidas de mercado para parâmetro de desempenho, já que estas estariam livres de manipulação, porém, medidas de mercado são constantemente influenciadas por fatores fora do controle do gestor, como questões macroeconômicas, evidenciando a possibilidade do mesmo ser remunerado por “sorte”. (BERTRAND; MULLAINATHAN, 2001). Além disso, o uso de medidas financeiras foca o esforço do executivo no retorno de curto prazo, e não na geração de valor de longo prazo. (SLIWKA, 2002; JENSEN et al., 2004; DIKOLLI; VAYSMAN, 2006).

Outra maneira de atrelar a remuneração ao desempenho empresarial é a remuneração com opção de ações. Esse mecanismo divide o risco entre o gestor e os acionistas, à medida que qualquer flutuação negativa do preço da ação irá impactar negativamente na remuneração do CEO (MURPHY, 1999).

\subsection{Governança Corporativa e Compensação}

Governança corporativa e políticas de remuneração estão intrinsecamente relacionadas. Onde uma má governança corporativa pode colaborar para a destruição de valor das empresas através de más práticas de compensação (JENSEN et al., 2004).

Uma das medidas mais importantes de governança corporativa na atualidade é o desvio de direitos, onde o controlador possui um número inferior de ações que proporcionam o controle, frente ao total de ações da firma. Esse desvio do direito a voto e o direito a fluxo de caixa, incentiva o controlador a expropriar riqueza dos investidores (CHEN et al., 2011).

Algumas situações são apontadas como questões de governança corporativa que buscam limitar o poder do CEO e evitar remunerações que representem perda de valor para o acionista. Uma delas é o tamanho do conselho. A literatura aponta que conselhos de administração grandes efetuam um menor monitoramento por ser mais fácil do CEO exercer influência sobre os conselheiros, conseguindo assim, decidir sua própria remuneração. (YERMACK, 1995; CORE et al., 1999).

Muito se argumenta acerca da independência dentro do conselho de administração, porém, a teoria e as evidências são conflitantes. A remuneração dos executivos seria maior quando o número de membros do conselho independentes fosse maior, pois além ser indicada pelo CEO, existe também a facilidade de os conselheiros 
independentes compreenderem melhor a importância do incentivo e da remuneração para o trabalho do CEO (YERMACK, 1996; MEHRAN, 1995). Todavia, um maior número de conselheiros independentes pode exercer um maior monitoramento e, com isso, evitar remunerações acima do mercado para os CEO’S. (CYERT et al., 2002).

Também se observa que se o CEO ocupar simultaneamente a cadeira de presidente do conselho e a de diretor presidente da empresa, o mesmo tenderá a ter influência suficiente para definir a sua própria remuneração, podendo muitas vezes ocasionar em perda de valor para o acionista (GOYAL; PARK, 2002; CYERT et al., 2002).

Existe também uma questão comportamental, a influência do CEO sobre o conselho de administração pode ser devido a uma pré-disposição do ser humano à obediência. Logo, para anular essa influência seria necessário alguém com a mesma posição do CEO dentro do conselho, a exemplo de um ex-presidente (MORCK, 2008).

\subsection{Controle acionário e compensação}

Além da ótica do conflito de agência entre proprietário e gestor, é importante também estudá-lo pela ótica do acionista controlador versus o acionista minoritário (SHLEIFER; VISHNY, 1997). Jensen e Meckling (1976) apontam que uma maior concentração de instrumentos patrimoniais em um único acionista, o faria ter maiores condições e maiores benefícios em fiscalizar o agente, de modo que essa fiscalização reduziria os custos de agência, e, somente com uma alta concentração acionária, o benefício de fiscalizar superaria os custos.

Morck et al. (1988) identificaram os benefícios na concentração do controle, onde os custos de agência iriam ser mitigados pois não haveria conflito de interesses. Bebchuk e Fried (2005) afirmam que uma concentração acionária em um só acionista iria reduzir os custos de agência, principalmente no que diz respeito à capacidade do CEO em estipular a própria remuneração, pois esse não teria como usar sua influência. Entretanto, não há consenso na literatura quanto aos benefícios de se ter uma alta concentração acionária.

Um alto controle acionário também pode ser parte do conflito de agência, devido à capacidade de o controlador dispender recursos em atividades lucrativas somente para ele, como, por exemplo, emprestar dinheiro a firmas as quais ele também participa a juros menores do que os de mercado e contratar CEO de sua família usando a 
remuneração paga ao mesmo como forma de expropriar os acionistas (BEBCHUK; FRIED, 2005; MORCK et al., 2003)

Quando a concentração acionária não é dispersa e o controle não pode ser associado a uma pessoa, poucos acionistas têm incentivos para monitorar as ações do gestor. Já quando o controle acionário é concentrado em poucos acionistas, estes têm uma melhor relação custo-benefício para fiscalizar o gestor.

Além da concentração acionária, o tipo de controlador também pode influenciar no problema de agência. Quatro tipos de controlador são comumente tratados na literatura: firmas familiares, instituições, governos e firmas sem controlador.

Em firmas de controle familiar o CEO agirá dentro dos interesses da família, muitas vezes em detrimento dos interesses dos acionistas minoritários, dessa forma, a compensação do executivo estará alinhada aos interesses da família. (BARONTINI; BOZZI, 2011). De forma geral, a família terá o interesse de aumentar o valor da firma, afinal, é o seu patrimônio, muitas vezes carregando no nome a reputação familiar. (DAVIS et al., 1997; CORBETTA; SALVATO, 2004; DYER; WHETTEN, 2006), como também o patrimônio será deixado para gerações futuras (CASSON, 1999; JAMES, 1999). Assim, em firmas familiares a relação da compensação dos executivos com o desempenho da firma deveria ser estritamente relacionada. Porém, os interesses da família podem colidir com os interesses do acionista minoritário, e dessa forma a remuneração dos executivos pode ser utilizada como forma de expropriação de riqueza (BURKART et al., 2003).

Quando o controle da empresa pertence a uma instituição, como um banco ou fundo de investimento, parte do retorno de sua carteira depende do retorno de seu investimento. Assim, se uma firma que o mesmo controla apresentar um desempenho insatisfatório, isso representará perdas maiores do que somente o resultado da empresa (COFFE, 1991). Devido a esse fato, investidores institucionais têm maiores incentivos que outros acionistas para fiscalizar a gestão da empresa, além de uma maior expertise do negócio. (CUBBIN; LEECH, 1983; BATHALA, 1996; CARLETON et al., 1998). Dessa forma, espera-se que a remuneração dos executivos em firmas institucionais esteja mais relacionada ao desempenho empresarial.

Quanto ao controle governamental, os objetivos de uma firma de controle privado e de uma firma de controle governamental podem ser diferentes, pois, os objetivos de uma empresa governamental variam entre maximização da riqueza do 
acionista, manutenção de atividades de bem estar geral e monopólios de indústrias importantes para o país (CLARKE, 2003).

Diante disso, os planos de remuneração de executivos podem diferir significativamente, pois, além de diferentes objetivos, os CEO’s geralmente são funcionários públicos com salários fixos ou servidores indicados pelo governo (FAN et al., 2011)

Por fim, para firmas sem controlador, devido ao fraco incentivo de fiscalização dos acionistas, espera-se que o CEO seja capaz de determinar a própria remuneração, e elevá-la a níveis não condizentes com o desempenho empresarial (BERTRAND; MULLAINATHAN, 2001; BEBCHUK; FRIED, 2005).

\subsection{Revisão da literatura empírica}

No campo empírico, a relação entre remuneração e desempenho empresarial é intensamente estudada. Há evidências de que a remuneração paga é diretamente relacionada ao desempenho da empresa, como sugere Kato e Kubo (2006) e Zhou (2000) respectivamente no mercado japonês e no mercado canadense. Essa relação se comprova a partir do uso de métricas para mensurar o desempenho. Niap e Taylor (2012) encontraram que a remuneração tem maior ligação com dois indicadores contábeis, o Retorno sobre o Patrimônio Líquido (ROE) e Fluxo de Caixa Líquido. Ke et al. (1999) também encontrou relação entre o ROA e compensação de executivos.

Zakaria (2012) encontrou maior relação com medidas de mercado, como Lucro por Ação (LPA) e Retorno Total, corroborando o estudo de Baber et al. (1996) que também encontrou melhor relação da remuneração com métricas de desempenho relacionadas ao mercado em detrimento das contábeis. Mishra et al. (2000) também encontrou relação entre a remuneração percebida e o desempenho empresarial, mas, identificou que essa relação diminui à medida que o valor pago a título de remuneração, aumenta. Lee (2009), em estudo realizado na Inglaterra, reporta relação positiva entre desempenho e remuneração, ressaltando que o seu estudo foi realizado em mercado considerado desenvolvido, o que segundo o autor justifica a relação.

Tosi et al. (2004), diferentemente dos estudos supracitados, não encontrou relação entre remuneração e desempenho, e sim entre remuneração e carisma do CEO, mesmo controlando para o desempenho. Duffhues e Kabir (2008) evidenciaram que na Holanda a remuneração dos gestores era inversa ao seu desempenho, ou seja, quanto 
pior o resultado da companhia, maior era a remuneração do gestor. Os autores justificam o resultado encontrado a não existência de um ambiente hostil para os CEO's, como a ausência de takeover's ou a possibilidade dos CEO’s estarem arbitrando sua própria remuneração a partir de sua influência. Fernandes (2008) por sua vez, não encontrou nenhuma relação entre remuneração e desempenho em Portugal, justificando essa ausência de relação devido à forma com que as firmas se financiam, como o mercado não é fonte primaria de recursos, eles não utilizam métricas de mercado ou contábeis para medir o desempenho dos CEO’s.

Quanto a relação entre controle acionário e remuneração percebida, Haid e Yurtoglu (2006) encontraram para o mercado alemão, no período de 1987 a 2003, uma relação positiva entre controle familiar e remuneração da diretoria, enquanto o controle por instituições apresentou relação negativa com a remuneração da diretoria. Barontini e Bozzi (2011), numa amostra de firmas italianas, também encontram forte relação positiva entre o controle familiar e o volume de remuneração pago à diretoria.

Santerre e Neun (1989) observaram uma relação negativa entre concentração acionária e compensação dos CEOS no mercado americano. Dyl (1988) também encontrou relação negativa entre concentração acionária e remuneração dos gestores. Na mesma linha de estudos, Haye (1997) afirma que a presença de blockholders (acionistas com um grande bloco de ações) impacta de forma negativa no montante pago ao CEO, com o que corroboram Firth et al. (2007) e Kraft e Niederprum (1999).

Estudos mais recentes como John et al. (2010) examinaram a relação entre blockholders e a remuneração, numa amostra de bancos americanos no período de 1992 a 2000 e encontraram relação positiva entre eles. Kim (2010) encontrou resultados similares utilizando companhias de seguros dos EUA no período de 1994 a 1996, enquanto no Brasil, Pinto e Leal (2013) encontraram relação inversa entre a concentração acionária e a remuneração de executivos.

Quanto a relação entre investidores institucionais e compensação, Hartzell e Starks (2003) encontraram relação negativa numa amostra de firmas americanas dentro do período de 1992 a 1997, sugerindo que os investidores institucionais mitigavam os custos de agência pois exerciam um maior monitoramento em relação a diretoria, evitando uma remuneração em excesso. Khan et al. (2005) concluíram que as firmas que possuíam controlador ou propriedade institucional pagavam maior remuneração a seus gestores, e também eram as que mais utilizavam mecanismos de compensação. Por sua vez Clay (2000) não encontrou relação entre este tipo de controle e remuneração. 
Cao et al. (2011), numa amostra de empresas do mercado chinês, verificaram que quanto maior o desvio de direitos, menor a remuneração dos executivos, e também que em firmas de controle governamental, a remuneração tem maior ligação com indicadores contábeis do que com os de mercado. O estudo de Cao et al. (2011) corroborou o trabalho de Kato e Long (2005) que também encontrou essa relação nas firmas de controle governamental.

No Brasil, o capital concentrado, seja na forma direta ou indireta, é característica das empresas que negociam ações na Bolsa de Valores Mobiliários (STERNBERG; LEAL; BORTOLON, 2011).

Com relação a remuneração do CEO e medidas de governança corporativa, Core et al. (1999) encontraram relação significativa entre a estrutura do conselho de administração e compensação. Neste processo, quanto maior o conselho, menor a remuneração do CEO e quanto maior a proporção de independentes, menor a remuneração, considerando uma amostra com empresas americanas. Tal estudo obteve resultados diferentes dos estudos de Yermack (1996) e Cyert et al. (2002).

Quando o CEO também é presidente do conselho de administração, Goyal e Park (2002) encontraram menor relação remuneração-desempenho, e Cyert et al. (2002) evidenciaram que a remuneração em empresas nessa condição, são maiores que a remuneração nas companhias onde o CEO não ocupa a posição de presidente do conselho de administração.

O quadro 1 apresenta um resumo dos principais estudos realizados. É possível perceber uma tendência nos estudos mais recentes em seguir uma metodologia de painel de dados, sendo basicamente estudos longitudinais e com painéis dinâmicos, em detrimento dos estudos cross-seccionais (DEVERS et al., 2007). 
Quadro 1 - Resumo dos principais estudos empíricos acerca de compensação de executivos

\begin{tabular}{|c|c|c|c|c|}
\hline Autores/Ano & Objetivo & Metodologia & Métricas & Resultados \\
\hline $\begin{array}{l}\text { Santerre e Neun } \\
\text { (1986) }\end{array}$ & $\begin{array}{l}\text { Verificar se a } \\
\text { dispersão } \\
\text { acionária } \\
\text { influência a } \\
\text { remuneração dos } \\
\text { executivos }\end{array}$ & $\begin{array}{l}\text { Regressão linear } \\
\text { com uma } \\
\text { amostra de } 68 \\
\text { empresas } \\
\text { americanas, os } \\
\text { autores não } \\
\text { dizem o período }\end{array}$ & $\begin{array}{l}\text { Remuneração, total } \\
\text { do ativo, ROS, } \\
\text { Índice de Herfindal }\end{array}$ & $\begin{array}{l}\text { Encontrou relação } \\
\text { inversa entre a } \\
\text { concentração } \\
\text { acionária e o nível } \\
\text { de compensação } \\
\text { recebido pelos } \\
\text { gestores }\end{array}$ \\
\hline Ke et al. (1999) & $\begin{array}{l}\text { Investigar a } \\
\text { relação entre } \\
\text { compensação de } \\
\text { executivos e } \\
\text { desempenho, em } \\
\text { função da } \\
\text { estrutura de } \\
\text { propriedade no } \\
\text { mercado chinês }\end{array}$ & $\begin{array}{l}\text { Regressão linear } \\
\text { nos anos de } 1994 \\
\text { a } 1996\end{array}$ & $\begin{array}{l}\text { Remuneração, } \\
\text { Dummy para } \\
\text { concentração } \\
\text { acionária, Total do } \\
\text { ativo, ROA }\end{array}$ & $\begin{array}{l}\text { Encontrou relação } \\
\text { positiva entre } \\
\text { desempenho, } \\
\text { tamanho e } \\
\text { remuneração em } \\
\text { firmas com o } \\
\text { capital disperso, } \\
\text { enquanto essa } \\
\text { relação não } \\
\text { existia em firmas } \\
\text { de capital } \\
\text { concentrado }\end{array}$ \\
\hline Zhou (2000) & $\begin{array}{l}\text { Investigar a } \\
\text { relação entre } \\
\text { compensação de } \\
\text { executivos, } \\
\text { tamanho e } \\
\text { performance } \\
\text { corporativa no } \\
\text { mercado } \\
\text { canadense }\end{array}$ & $\begin{array}{l}\text { Dados em painel } \\
\text { no período de } \\
1991 \text { a } 1995\end{array}$ & $\begin{array}{l}\text { Remuneração, } \\
\text { Total do ativo, } \\
\text { Vendas, ROA, } \\
\text { ROE, Retorno da } \\
\text { ação }\end{array}$ & $\begin{array}{l}\text { Encontrou relação } \\
\text { positiva entre } \\
\text { desempenho, } \\
\text { tamanho e } \\
\text { remuneração }\end{array}$ \\
\hline $\begin{array}{l}\text { Mishra et al. } \\
\text { (2000) }\end{array}$ & $\begin{array}{l}\text { Verificar se o } \\
\text { atrelamento da } \\
\text { remuneração ao } \\
\text { desempenho } \\
\text { melhora o } \\
\text { desempenho } \\
\text { empresarial }\end{array}$ & $\begin{array}{l}\text { Regressão linear, } \\
\text { com empresas } \\
\text { americanas no } \\
\text { período de 1974- } \\
1988\end{array}$ & $\begin{array}{l}\text { Performance, } \\
\text { Risco, } \\
\text { remuneração }\end{array}$ & $\begin{array}{l}\text { Encontrou que os } \\
\text { executivos são } \\
\text { avessos ao risco, } \\
\text { e quando a } \\
\text { remuneração é } \\
\text { muito atrelada ao } \\
\text { desempenho, a } \\
\text { empresa tem um } \\
\text { desempenho } \\
\text { inferior. }\end{array}$ \\
\hline $\begin{array}{l}\text { Khan et al. } \\
\text { (2005) }\end{array}$ & $\begin{array}{l}\text { Investigar como a } \\
\text { propriedade } \\
\text { institucional afeta } \\
\text { a remuneração do } \\
\text { CEO }\end{array}$ & $\begin{array}{l}\text { Painel de dados } \\
\text { com firmas } \\
\text { americanas no } \\
\text { período de 1992- } \\
1999\end{array}$ & $\begin{array}{l}\text { Remuneração, } \\
\text { vendas, } \\
\text { crescimento, \% de } \\
\text { ações do maior } \\
\text { investidor } \\
\text { institucional, } \\
\text { número de } \\
\text { investidores } \\
\text { institucionais, total } \\
\text { de ações de } \\
\text { propriedade } \\
\text { institucional }\end{array}$ & $\begin{array}{l}\text { Encontrou que } \\
\text { uma concentração } \\
\text { acionária leva a } \\
\text { uma menor } \\
\text { remuneração, e } \\
\text { que propriedade } \\
\text { institucional leva } \\
\text { a uma maior } \\
\text { remuneração e } \\
\text { um maior uso de } \\
\text { remuneração } \\
\text { variável }\end{array}$ \\
\hline
\end{tabular}


Continuação do Quadro 1

\begin{tabular}{|c|c|c|c|c|}
\hline $\begin{array}{l}\text { Kato e Kubo } \\
\text { (2006) }\end{array}$ & $\begin{array}{l}\text { Verificar se existe } \\
\text { relação entre } \\
\text { desempenho e } \\
\text { remuneração dos } \\
\text { gestores dentro do } \\
\text { mercado japonês }\end{array}$ & $\begin{array}{l}\text { Painel de } \\
\text { dados de } \\
1985 \text { a } 1995 .\end{array}$ & $\begin{array}{l}\text { Remuneração, } \\
\text { ROA, crescimento } \\
\text { de vendas, número } \\
\text { de empregados, } \\
\text { Retorno da ação }\end{array}$ & $\begin{array}{l}\text { Relação positiva entre } \\
\text { desempenho mensurado } \\
\text { pelo ROA e } \\
\text { remuneração dos } \\
\text { executivos }\end{array}$ \\
\hline $\begin{array}{l}\text { Haid e } \\
\text { Yortoglu } \\
\text { (2006) }\end{array}$ & $\begin{array}{l}\text { Investigar a } \\
\text { relação entre } \\
\text { estrutura de } \\
\text { propriedade e } \\
\text { compensação de } \\
\text { executivos }\end{array}$ & $\begin{array}{l}\text { Dados em } \\
\text { painel, com } \\
\text { uma amostra } \\
\text { de } 400 \text { firmas } \\
\text { alemãs no } \\
\text { período de } \\
\text { 1987-2003 }\end{array}$ & $\begin{array}{l}\text { Remuneração, } \\
\text { Total do ativo, n de } \\
\text { empregados, } \\
\text { vendas, ROA, } \\
\text { Retorno da ação, } \\
\text { Concentração } \\
\text { acionária. }\end{array}$ & $\begin{array}{l}\text { A compensação nas } \\
\text { firmas alemãs aumentou } \\
\text { consideravelmente no } \\
\text { período de } 1987 \text { para } \\
\text { 2003. O tamanho da } \\
\text { empresa é mais } \\
\text { importante para } \\
\text { determinar a } \\
\text { compensação do que o } \\
\text { desempenho, e uma alta } \\
\text { concentração acionária } \\
\text { diminui a possibilidade } \\
\text { do executivo de extrair } \\
\text { altas remunerações }\end{array}$ \\
\hline $\begin{array}{l}\text { Firth et al. } \\
\text { (2007) }\end{array}$ & $\begin{array}{l}\text { Investigar se a } \\
\text { remuneração do } \\
\text { gestor depende da } \\
\text { performance e se } \\
\text { o tipo de } \\
\text { controlador tem } \\
\text { impacto na } \\
\text { relação - } \\
\text { remuneração- } \\
\text { desempenho }\end{array}$ & $\begin{array}{l}\text { Dados em } \\
\text { painel com } \\
549 \text { firmas do } \\
\text { mercado } \\
\text { chinês no } \\
\text { período de } \\
1997 \text { a } 2000\end{array}$ & $\begin{array}{l}\text { Remuneração, } \\
\text { ROA, retorno da } \\
\text { ação, Se a firma é } \\
\text { estatal ou } \\
\text { estrangeira, } \\
\text { independência do } \\
\text { conselho, tamanho } \\
\text { do conselho, chair } \\
\text { duality, risco, total } \\
\text { do ativo, } \\
\text { crescimento e } \\
\text { divida }\end{array}$ & $\begin{array}{l}\text { Encontrou relação } \\
\text { positiva entre } \\
\text { remuneração e ROA, e } \\
\text { que o CEO recebe menos } \\
\text { compensação se a firma } \\
\text { for de propriedade do } \\
\text { governo }\end{array}$ \\
\hline $\begin{array}{l}\text { Duffhues e } \\
\text { Kabir } \\
\text { (2008) }\end{array}$ & $\begin{array}{l}\text { Investigar a } \\
\text { relação entre } \\
\text { remuneração e } \\
\text { desempenho na } \\
\text { Holanda }\end{array}$ & $\begin{array}{l}\text { Regressão } \\
\text { linear com } \\
\text { amostra de } \\
\text { empresas do } \\
\text { mercado } \\
\text { holandês no } \\
\text { período de } \\
\text { 1998-2001 }\end{array}$ & $\begin{array}{l}\text { Remuneração, } \\
\text { ROA, ROS, } \\
\text { Market-to-book, Q } \\
\text { de Tobin, } \\
\text { Alavancagem, } \\
\text { Total do ativo }\end{array}$ & $\begin{array}{l}\text { Encontrou resultados } \\
\text { consistentes com a teoria } \\
\text { de que o gestor consegue } \\
\text { arbitrar sua } \\
\text { remuneração, à medida } \\
\text { que desempenhos } \\
\text { inferiores levavam a uma } \\
\text { maior remuneração }\end{array}$ \\
\hline
\end{tabular}




\begin{tabular}{|c|c|c|c|c|}
\hline $\begin{array}{l}\text { Fernandes } \\
\text { (2008) }\end{array}$ & $\begin{array}{l}\text { Investigar a } \\
\text { relação entre } \\
\text { compensação de } \\
\text { executivos, } \\
\text { governança } \\
\text { corporativa e } \\
\text { desempenho }\end{array}$ & $\begin{array}{l}\text { Dados em } \\
\text { painel com } 58 \\
\text { empresas } \\
\text { listadas na } \\
\text { Euronext, no } \\
\text { período de } \\
2002 \text { a } 2004\end{array}$ & $\begin{array}{l}\text { Remuneração, Total } \\
\text { do ativo, Risco da } \\
\text { ação, Book-to- } \\
\text { Market, } \\
\text { Independência do } \\
\text { conselho }\end{array}$ & $\begin{array}{l}\text { Encontrou que } \\
\text { firmas com menos } \\
\text { conselheiros } \\
\text { independentes tem } \\
\text { melhor relação } \\
\text { entre remuneração e } \\
\text { desempenho, e um } \\
\text { maior alinhamento } \\
\text { de interesses }\end{array}$ \\
\hline $\begin{array}{l}\text { Barontini e } \\
\text { Bozzi (2011) }\end{array}$ & $\begin{array}{l}\text { Verificar se a } \\
\text { remuneração é } \\
\text { utilizada como } \\
\text { forma de } \\
\text { expropriar os } \\
\text { acionistas em } \\
\text { firmas de controle } \\
\text { familiar }\end{array}$ & $\begin{array}{l}\text { Dados em } \\
\text { painel com } \\
\text { uma amostra } \\
\text { de } 175 \text { firmas } \\
\text { italianas no } \\
\text { período de } \\
\text { 1998-2002 }\end{array}$ & $\begin{array}{l}\text { Controle familiar, } \\
\text { concentração } \\
\text { acionária, desvio de } \\
\text { direitos, existência } \\
\text { de acordo de } \\
\text { acionistas, tamanho, } \\
\text { retorno da ação, } \\
\text { ROA, Risco da } \\
\text { ação, presença de } \\
\text { remuneração com } \\
\text { opções, } \\
\text { Chairduality, } \\
\text { tamanho do } \\
\text { conselho }\end{array}$ & $\begin{array}{l}\text { Encontrou que a } \\
\text { remuneração dos } \\
\text { CEO’s em firmas de } \\
\text { controle familiar é } \\
\text { maior, e estão } \\
\text { relacionadas a um } \\
\text { pior desempenho, } \\
\text { indicando uma } \\
\text { possível forma de } \\
\text { expropriação de } \\
\text { riqueza do } \\
\text { minoritário }\end{array}$ \\
\hline $\begin{array}{l}\text { Zakaria } \\
\text { (2012) }\end{array}$ & $\begin{array}{l}\text { Identificar as } \\
\text { variáveis de } \\
\text { performances que } \\
\text { são utilizadas pelas } \\
\text { empresas para } \\
\text { remunerar seus } \\
\text { gestores, no } \\
\text { mercado britânico }\end{array}$ & $\begin{array}{l}\text { Análise } \\
\text { descritiva no } \\
\text { período de } \\
2002 \text { a } 2003\end{array}$ & & $\begin{array}{l}\text { Encontrou que as } \\
\text { medidas mais } \\
\text { utilizadas são } \\
\text { ganhos por ação, e } \\
\text { retorno total da ação }\end{array}$ \\
\hline $\begin{array}{l}\text { Niap e Taylor } \\
\text { (2012) }\end{array}$ & $\begin{array}{l}\text { Investigar se em } \\
\text { períodos de } \\
\text { turbulência } \\
\text { econômica importa } \\
\text { mais a reputação } \\
\text { do CEO ou as } \\
\text { métricas de } \\
\text { performance e } \\
\text { governança }\end{array}$ & $\begin{array}{l}\text { Regressão } \\
\text { linear nos } \\
\text { anos de } 2009 \\
\text { a } 2011\end{array}$ & $\begin{array}{l}\text { Remuneração, } \\
\text { reputação do CEO, } \\
\text { Independência do } \\
\text { conselho de } \\
\text { administração, } \\
\text { blockholders, ROA, } \\
\text { ROE, Retorno da } \\
\text { ação, Dividendo por } \\
\text { ação, Total do ativo }\end{array}$ & $\begin{array}{l}\text { Os resultados } \\
\text { revelam } \\
\text { significância da } \\
\text { reputação quanto ao } \\
\text { pagamento, junto a } \\
\text { volatilidade do } \\
\text { ROE e fluxo de } \\
\text { caixa líquido para a } \\
\text { determinação da } \\
\text { remuneração }\end{array}$ \\
\hline
\end{tabular}

Fonte: Elaborado pelo autor. 


\section{PROCEDIMENTOS METODOLÓGICOS}

3.1 Os determinantes da remuneração e a influência do tipo de controle

Para identificar a relação entre controle acionário e remuneração dos executivos foram estimados dois grupos de modelos econométricos, sendo cada um composto por quatro equações. Em virtude das informações disponíveis das empresas serem anuais, foram adotados alguns procedimentos de adequação, considerando apenas àquelas que dispunham de informações necessárias ao longo do período, no intuito de que a estrutura dos dados permitisse a análise de dados em painel. Sendo assim, formou-se uma amostra balanceada com 224 empresas distribuídas ao longo do período de 2010 a 2013.

No primeiro grupo de modelos estimados, o objetivo foi estimar os determinantes de cada tipo de controle (familiar, governo, institucional e capital difuso), representada pela variável $x$.

O modelo estimado foi o seguinte:

$\operatorname{RemTot}_{i t, x}=\beta_{0}+\beta_{1} \operatorname{Tam}_{i t}+\beta_{2}$ ROA $_{i t}+\beta_{3} \operatorname{Conc}_{i t}+\beta_{4} G_{i t}+\delta_{t}+\varepsilon_{i t}$

Já no segundo grupo de modelos, procurou-se estimar a influência de cada tipo de controle (familiar, governo, institucional e capital difuso) na remuneração executiva. Os modelos estimados foram:

RemTot $_{i t}=\beta_{0}+\beta_{1} \operatorname{Tam}_{i t}+\beta_{2}$ ROA $_{i t}+\beta_{3} \operatorname{Conc}_{i t}+\beta_{4} G_{i t}+\beta_{5} X_{i t}+\delta_{t}+\varepsilon_{i t}(2)$

A variável dependente RemTot refere-se a quantidade total paga de remuneração fixa e variável à diretoria executiva. A variável RemTot foi obtida através do logaritmo da soma dos valores pagos a título de remuneração fixa e variável. No que respeita as variáveis independentes, a variável Tam é utilizada como proxy para tamanho da empresa, a variável ROA (Retorno sobre o Ativo) representa o retorno gerado pelo uso dos ativos, a variável Conc refere-se a concentração acionária na empresa, a variável $G$ representa variáveis do grupo de Governança Corporativa, o vetor $X i$ indica o grupo de variáveis alusiva ao tipo de controle (familiar, governo, institucional e capital difuso), 
$\delta_{t}$ é o componente temporal e $\varepsilon_{i t}$ são choques aleatórios normais e independentes ao longo do tempo. Por fim, os subscritos $i$ e $t$ referem-se às empresas e aos anos.

Detalhando as variáveis inseridas no vetor $X i$, referente ao tipo de controle, é importante enfatizar que a sua identificação foi feita a partir do formulário de referências, uma vez que este demonstra quem é o controlador e os maiores detentores de instrumentos patrimoniais da entidade. Para isso considerou-se as seguintes variáveis: a) dContFam (Controle familiar) variável utilizada para discriminar se o controlador da empresa é familiar, sendo considerado 1 se o controlador da empresa for pessoa física ou jurídica, detentor de mais de 50\% de ações com poder de voto, mesmo quando uma família detiver o controle a partir de uma arquitetura piramidal e 0 caso contrário; b) dContIns (Controle institucional) variável que se refere ao controlador institucional, assumindo valor 1 caso a empresa seja controlada por bancos de desenvolvimento, mesmo que estatais, fundos de investimento, de previdência, tanto nacionais quanto estrangeiros; c) dContGov (Controle governamental) variável representativa para o caso de o controlador ser a União, Estado ou município, assumindo valor igual a 1, e 0 caso contrário; d) dCapDifuso (Capital difuso) variável utilizada para caracterizar uma empresa que não possui um acionista controlador, nem de forma direta nem de forma indireta, recebendo valor 1 caso não exista controlador e 0 caso contrário.

Em relação às variáveis do grupo de Governança Corporativa (Gi) foram utilizadas: a) $C D$ - variável dummy que assumirá valor 1 para se o diretor presidente (CEO) ocupar simultaneamente a cadeira de presidente do conselho de administração e 0 caso contrário; ii) IndCons - variável indicadora do percentual do conselho de administração independente, utilizada como proxy para mensuração da função de fiscalização por parte do conselho de administração. Por fim, as variáveis TAM e ROA são, respectivamente, uma proxy comumente utilizada na literatura para o tamanho da empresa, sendo contabilizada através do logaritmo do ativo total enquanto o ROA (Retorno sobre o Ativo) é uma medida amplamente utilizada para representar o retorno gerado pelo uso dos ativos, sendo calculada pela razão entre o lucro liquido e o ativo total.

Todas as variáveis inseridas no modelo possuem, de acordo com a teoria, elementos que as qualificam como importantes determinantes da remuneração total dos executivos. Discussões acerca de suas relações com a remuneração total foram expostas no capítulo anterior e serão ainda mais detalhadas ao longo da análise dos resultados, 
sempre tendo como referencial os artigos citados no quadro abaixo. O quadro abaixo traz um resumo das variáveis independentes utilizadas nos modelos, e sua codificação, além de seus respectivos sinais esperados.

Quadro 2 - Resumo das variáveis independentes utilizadas, e seus respectivos sinais esperados, na estimação dos modelos de determinação da remuneração da diretoria executiva

\begin{tabular}{|c|c|c|c|c|}
\hline \multicolumn{2}{|r|}{ Variável } & Métrica da variável & Utilizado por & $\begin{array}{c}\text { Sinal } \\
\text { esperado }\end{array}$ \\
\hline TAM & $\begin{array}{c}\text { TAM } \\
\text { (Tamanho) }\end{array}$ & Logaritmo do Ativo total & $\begin{array}{l}\text { Haid e Yortoglu (2006); } \\
\text { Duffhues e Kabir (2008) }\end{array}$ & + \\
\hline ROA & $\begin{array}{c}\text { ROA } \\
\text { (Retorno sobre Ativo) }\end{array}$ & $\begin{array}{c}\text { Lucro Líquido / Total do } \\
\text { Ativo }\end{array}$ & $\begin{array}{l}\text { Yermack (1996); Ke et } \\
\text { al. (1999); Cao et al. } \\
\text { (2011); Duffhues e Kabir } \\
\text { (2008); Cyert et al. } \\
\text { (2002) }\end{array}$ & + \\
\hline Conc & $\begin{array}{c}\text { Conc } \\
\text { (Concentração acionária) }\end{array}$ & $\begin{array}{c}\text { Soma do capital detido } \\
\text { pelos } 5 \text { maiores } \\
\text { acionistas, que detiverem } \\
\text { ao menos } 5 \% \text { do capital } \\
\text { da empresa }\end{array}$ & $\begin{array}{l}\text { Haye (1997); Santerre e } \\
\text { Neun (1989); Dyl (1998); } \\
\text { Kraft e Niederprum } \\
\text { (1999); Firth John et al. } \\
\text { (2007); John et al. } \\
\text { (2010); Kim (2010); } \\
\text { Pinto e Leal (2013) }\end{array}$ & + \\
\hline \multirow[t]{2}{*}{$\mathrm{Gi}$} & $\begin{array}{c}\text { CD } \\
\text { (ChairDuality) }\end{array}$ & $\begin{array}{c}1 \text { para se o diretor } \\
\text { presidente ocupa } \\
\text { simultaneamente a } \\
\text { cadeira de presidente do } \\
\text { conselho, } 0 \text { caso contrário }\end{array}$ & $\begin{array}{l}\text { Yermack (1996); Cyert et } \\
\text { al., (2002); Goyal e Park } \\
\text { (2002) }\end{array}$ & + \\
\hline & $\begin{array}{c}\text { IndCons } \\
\text { (Independência do conselho } \\
\text { de administração) }\end{array}$ & $\begin{array}{l}\text { Percentual do conselho de } \\
\text { ADM que é independente }\end{array}$ & $\begin{array}{l}\text { Yermack (1996); Cyert et } \\
\text { al. (2002); Jensen (2011) }\end{array}$ & - \\
\hline \multirow{4}{*}{$\mathrm{Xi}$} & $\begin{array}{c}\text { dContFam } \\
\text { (Controle Familiar) }\end{array}$ & $\begin{array}{c}1 \text { para empresa de } \\
\text { controle familiar, } 0 \text { caso } \\
\text { contrário }\end{array}$ & $\begin{array}{l}\text { Haid e Yurtoglu (2006); } \\
\text { Barontini e Bozzi (2011) }\end{array}$ & Indefinido \\
\hline & $\begin{array}{c}\text { dContIns } \\
\text { (Controle Institucional) }\end{array}$ & $\begin{array}{c}1 \text { para caso a empresa } \\
\text { seja controlada por } \\
\text { instituições, } 0 \text { caso } \\
\text { contrário }\end{array}$ & $\begin{array}{l}\text { Khan et al. (2005), John } \\
\text { et al. (2005); Firth et al. } \\
\text { (2007) }\end{array}$ & Indefinido \\
\hline & $\begin{array}{c}\text { dContGov } \\
\text { (Controle do Governo) }\end{array}$ & $\begin{array}{c}1 \text { para caso a empresa } \\
\text { seja controlada pelo } \\
\text { Governo, } 0 \text { caso contrário }\end{array}$ & $\begin{array}{l}\text { Kato e Long (2005) } \\
\text { Cao et al. (2011) }\end{array}$ & Indefinido \\
\hline & $\begin{array}{c}\text { dCapDifuso } \\
\text { (Ausência de controlador) }\end{array}$ & $\begin{array}{c}1 \text { para caso a empresa não } \\
\text { tenha controlador, } 0 \text { caso } \\
\text { contrário }\end{array}$ & Bebchuk e Fried (2005) & + \\
\hline
\end{tabular}

Fonte: Elaborado pelo autor. 


\subsection{Banco de dados}

Inicialmente, o universo da pesquisa seria caracterizado por todas as empresas que negociam seus instrumentos patrimoniais na BM\&FBOVESPA durante o período de 2010 a 2013. Todavia, após a coleta das informações acerca do preenchimento do Formulário de Referência - necessário para a obtenção das informações acerca da remuneração da diretoria executiva e governança corporativa - e dos dados referentes ao desempenho econômico-financeiro das empresas, coletados no Economática e nos demonstrativos contábeis, a amostra ficou restrita a 224 (Duzentas e vinte e quatro) empresas que disponibilizaram os dados necessários para a estimação dos determinantes da remuneração paga aos membros da diretoria executiva, de um total de 343 companhias com capital aberto na BM\&FBOVESPA. Assim, formou-se um painel balanceado com informações para os quatro anos do estudo, observando-se assim, a limitação de sobrevivência, visto que foram excluídas empresas que abriram ou fecharam durante este período. 


\section{ANÁLISE DOS RESULTADOS}

\subsection{Análise descritiva}

Como dito na metodologia, a amostra ficou restrita a 224 (duzentos e vinte e quatro) empresas que negociavam seus títulos no período de 2010 a 2013.

A tabela 1 traz a descrição dos dados tabulados por empresa, informando a média, desvio padrão, valor mínimo e valor máximo das varáveis, por ano. Em relação ao tipo de controlador, as empresas de controle familiar são 56\% da amostra, enquanto institucionais são 25\%, as que não possuem controlador são $11 \%$ e complementando a amostra, cerca de $8 \%$ são de controle governamental. Esses valores não variam significativamente entre os anos, demonstrando que existe pouca variação de tipo de controlador entre os anos.

A dualidade da diretoria é presente em $47 \%$ da amostra, enquanto a média de conselheiros independentes dentro do conselho de administração é de 22\%. Este resultado evidencia uma fraca governança dentro das empresas que negociam seus títulos na BM\&FBOVESPA.

Quanto à concentração acionária na amostra, os resultados mostram que em média de 66\% das ações estão concentradas nos 5 maiores acionistas, indicando uma alta concentração de capital.

Entre os anos, a remuneração total média paga a diretoria estatutária variou 1\% entre os anos de 2010 e 2011, em 2012 subiu 12\% em relação a 2011, e voltou a ter um crescimento reduzido de somente 4\% em 2013, em relação a 2012. O desvio-padrão maior que a média evidência a existência de heterogeneidade na remuneração das empresas da amostra.

Em relação ao tamanho, o valor médio mostra uma tendência de crescimento das empresas. Em 2011 observou-se um aumento de 13\% em relação a 2010, enquanto em 2012 foi 12\% em relação a 2011 e em 2013 foi de 9\% comparativamente a 2012. O valor médio do tamanho das empresas foi menor que o desvio padrão, indicando a existência de empresas de vários portes, reforçando a heterogeneidade da amostra. 
Tabela 1 - Estatística descritiva da amostra de empresas da BM\&FBOVESPA. 20102013

\begin{tabular}{|c|c|c|c|c|c|}
\hline Variável & $\begin{array}{c}\mathrm{N}^{0} \text { de } \\
\text { Empresas }\end{array}$ & Média & Desvio-padrão & Mínimo & Máximo \\
\hline \multicolumn{6}{|c|}{ Ano: 2010} \\
\hline Total da remuneração* & 224 & $19.300 .000,00$ & $119.000 .000,00$ & 4.627,32 & 1.720.000.000,00 \\
\hline Tamanho* & 224 & $10.000 .000,00$ & $45.200 .000,00$ & 437,00 & $520.000 .000,00$ \\
\hline ROA & 224 & 0,04 & 0,21 & $-1,57$ & 1,99 \\
\hline Concentração acionária & 224 & 0,65 & 0,20 & 0,07 & 1,00 \\
\hline Chair Duality & 224 & 0,44 & 0,49 & 0,00 & 1,00 \\
\hline Independência do conselho & 224 & 0,17 & 0,20 & 0,00 & 0,80 \\
\hline Controle Familiar & 224 & 0,57 & 0,50 & 0,00 & 1,00 \\
\hline Controle Institucional & 224 & 0,25 & 0,43 & 0,00 & 1,00 \\
\hline Ausência de controlador & 224 & 0,11 & 0,32 & 0,00 & 1,00 \\
\hline Controle de Governo & 224 & 0,08 & 0,27 & 0,00 & 1,00 \\
\hline \multicolumn{6}{|c|}{ Ano: 2011} \\
\hline Total da remuneração* & 224 & $19.4 \overline{00.000,00}$ & $95.900 .000,00$ & $12.720,00$ & 1.300.000.000,00 \\
\hline Tamanho* & 224 & $11.300 .000,00$ & $50.700 .000,00$ & 486,00 & $599.000 .000,00$ \\
\hline ROA & 224 & 0,03 & 0,14 & $-0,97$ & 0,86 \\
\hline Concentração acionária & 224 & 0,66 & 0,20 & 0,12 & 1,00 \\
\hline Chair Duality & 224 & 0,45 & 0,49 & 0,00 & 1,00 \\
\hline Independência do conselho & 224 & 0,19 & 0,22 & 0,00 & 0,86 \\
\hline Controle Familiar & 224 & 0,56 & 0,50 & 0,00 & 1,00 \\
\hline Controle Institucional & 224 & 0,25 & 0,44 & 0,00 & 1,00 \\
\hline Ausência de controlador & 224 & 0,11 & 0,31 & 0,00 & 1,00 \\
\hline Controle de Governo & 224 & 0,08 & 0,27 & 0,00 & 1,00 \\
\hline \multicolumn{6}{|c|}{ Ano: 2012} \\
\hline Total da remuneração* & 224 & $21.8 \overline{00.000,00}$ & $132.000 .000,00$ & $15.360,00$ & 1.890.000.000,00 \\
\hline Tamanho* & 224 & $12.700 .000,00$ & $56.300 .000,00$ & 513,00 & $678.000 .000,00$ \\
\hline ROA & 224 & 0,00 & 0,30 & $-3,57$ & 0,52 \\
\hline Concentração acionária & 224 & 0,66 & 0,20 & 0,12 & 1,00 \\
\hline Chair Duality & 224 & 0,45 & 0,49 & 0,00 & 4,00 \\
\hline Independência do conselho & 224 & 0,21 & 0,23 & 0,00 & 0,86 \\
\hline Controle Familiar & 224 & 0,55 & 0,50 & 0,00 & 1,00 \\
\hline Controle Institucional & 224 & 0,26 & 0,44 & 0,00 & 1,00 \\
\hline Ausência de controlador & 224 & 0,11 & 0,32 & 0,00 & 1,00 \\
\hline Controle de Governo & 224 & 0,08 & 0,27 & 0,00 & 1,00 \\
\hline \multicolumn{6}{|c|}{ Ano: 2013} \\
\hline Total da remuneração* & 224 & $22.7 \overline{00.000,00}$ & $132.000 .000,00$ & $16.688,00$ & 1.890.000.000,00 \\
\hline Tamanho* & 224 & $13.800 .000,00$ & $62.000 .000,00$ & 539,00 & 753.000.000,00 \\
\hline ROA & 224 & $-0,02$ & 0,36 & $-3,23$ & 0,80 \\
\hline Concentração acionária & 224 & 0,66 & 0,19 & 0,12 & 1,00 \\
\hline Chair Duality & 224 & 0,47 & 0,50 & 0,00 & 1,00 \\
\hline Independência do conselho & 224 & 0,22 & 0,21 & 0,00 & 0,80 \\
\hline Controle Familiar & 224 & 0,56 & 0,50 & 0,00 & 1,00 \\
\hline Controle Institucional & 224 & 0,25 & 0,44 & 0,00 & 1,00 \\
\hline Ausência de controlador & 224 & 0,11 & 0,32 & 0,00 & 1,00 \\
\hline Controle de Governo & 224 & 0,08 & 0,27 & 0,00 & 1,00 \\
\hline
\end{tabular}

Fonte: Economática e Formulário de Referências.

*Variáveis utilizadas em log no modelo econométrico.

A tabela 2 traz as estatísticas descritivas da remuneração das empresas de controle familiar. É possível observar uma tendência positiva na remuneração paga a diretoria das empresas familiares. No ano de 2011 a remuneração cresceu 14\% em relação a 2010, e em 2012, cerca de 3\% em relação a 2011, por fim em 2013 voltou a 
subir mais que $10 \%$, sendo observado um aumento de $11 \%$ em relação ao ano anterior. A remuneração das empresas familiares também possui um alto desvio padrão em relação à média, demonstrando a existência de empresas familiares com diferentes valores de remuneração.

Tabela 2 - Remuneração (em R\$) das empresas de controle familiar. 2010 a 2013

\begin{tabular}{cccccc}
\hline $\begin{array}{c}N^{\text {o de }} \\
\text { empresas }\end{array}$ & Ano & Média & Desvio-padrão & Mínimo & Máximo \\
\hline 127 & 2010 & $11.300 .000,00$ & $42.100 .000,00$ & $7.344,00$ & $436.000 .000,00$ \\
126 & 2011 & $12.600 .000,00$ & $48.900 .000,00$ & $12.720,00$ & $501.000 .000,00$ \\
124 & 2012 & $13.000 .000,00$ & $49.800 .000,00$ & $15.360,00$ & $530.000 .000,00$ \\
125 & 2013 & $14.400 .000,00$ & $52.700 .000,00$ & $16.688,00$ & $572.000 .000,00$ \\
\hline
\end{tabular}

Fonte: Economática e Formulário de Referências.

A tabela 3 refere-se a remuneração das empresas de controle institucional. Nesta também se verifica uma maior variação na remuneração paga a diretoria. No ano de 2011 a remuneração diminuiu 12\% em relação a 2010, enquanto em 2012 aumentou 21\% em relação a 2011, e em 2013 subiu cerca de 4\%. É importante ressaltar que para todos os anos, a remuneração média paga a diretoria de empresas institucionais foi no mínimo três vezes maior do que a remuneração média pelas empresas familiares da amostra.

Tabela 3 - Remuneração (em R\$) das empresas de controle institucional. 2010 a 2013

\begin{tabular}{cccccc}
\hline $\begin{array}{c}\text { N de } \\
\text { empresas }\end{array}$ & Ano & Média & Desvio-padrão & Mínimo & Máximo \\
\hline 55 & 2010 & $45.300 .000,00$ & $228.000 .000,00$ & $529.000,00$ & $1.720 .000 .000,00$ \\
57 & 2011 & $39.800 .000,00$ & $173.000 .000,00$ & $467.568,70$ & $1.300 .000 .000,00$ \\
58 & 2012 & $48.200 .000,00$ & $251.000 .000,00$ & $470.000,00$ & $1.890 .000 .000,00$ \\
57 & 2013 & $50.000 .000,00$ & $254.000 .000,00$ & $208.024,70$ & $1.890 .000 .000,00$ \\
\hline
\end{tabular}

Fonte: Economática e Formulário de Referências.

Na sequencia, a tabela 4 reporta estatística descritiva da remuneração das empresas que não possuem controlador. Nesta tabela não se verifica uma tendência de comportamento da remuneração paga a diretoria das empresas. Por exemplo, no ano de 2011 a remuneração aumentou consideravelmente, totalizando 29\% em relação a 2010, e em 2012 aumentou discretos 9\% em relação a 2011, enquanto em 2013 observou-se uma diminuição de 3\% na remuneração dos diretores. Comparativamente às empresas de controle institucional, as empresas com ausência de controlador pagam cerca de 70\% 
menos a seus diretores, porém, ainda remuneram na média, mais do que as empresas familiares.

Tabela 4 - Remuneração (em R\$) das empresas de ausência de controle. 2010 a 2013

\begin{tabular}{cccccc}
\hline $\begin{array}{c}\mathrm{N}^{\circ} \text { de } \\
\text { empresas }\end{array}$ & Ano & Média & Desvio-padrão & Mínimo & Máximo \\
\hline 25 & 2010 & $12.600 .000,00$ & $11.800 .000,00$ & $4.627,32$ & $51.800 .000,00$ \\
24 & 2011 & $16.300 .000,00$ & $13.900 .000,00$ & $2.119 .754,00$ & $52.900 .000,00$ \\
25 & 2012 & $17.800 .000,00$ & $15.200 .000,00$ & $1.576 .415,00$ & $45.200 .000,00$ \\
25 & 2013 & $17.300 .000,00$ & $14.400 .000,00$ & $2.090 .577,00$ & $57.200 .000,00$ \\
\hline
\end{tabular}

Fonte: Economática e Formulário de Referências.

Uma última tabela em relação ao tipo de controlador descreve a estatística da remuneração das empresas de controle governamental. A tabela 5 mostra que existe um aumento da remuneração média da diretoria, todavia o percentual deste aumento se reduz ao longo dos anos (18\% de 2011 a 2010, 14\% de 2012 a 2011 e 10\% de 2013 a 2012). Ao comparar com os outros tipos de controle, a diretoria das empresas de controle governamental são as que recebem a menor remuneração, sendo na média 4 vezes menor do que a remuneração paga pelas empresas familiares, 5 vezes menor que as com ausência de controlador e aproximadamente 10 vezes menor do que as de controle institucional.

Tabela 5 - Remuneração (em R\$) das empresas de controle governamental. 2010 a 2013

\begin{tabular}{cccccc}
\hline $\begin{array}{c}\mathrm{N}^{\text {o }} \text { de } \\
\text { empresas }\end{array}$ & Ano & Média & Desvio-padrão & Mínimo & Máximo \\
\hline 17 & 2010 & $2.911 .791,00$ & $2.217 .049,00$ & $626.236,80$ & $8.175 .926,00$ \\
17 & 2011 & $3.442 .899,00$ & $2.917 .472,00$ & $1.216 .686,00$ & $12.200 .000,00$ \\
17 & 2012 & $3.957 .493,00$ & $3.061 .120,00$ & $1.083 .751,00$ & $10.600 .000,00$ \\
17 & 2013 & $4.359 .976,00$ & $3.231 .825,00$ & $1.536 .669,00$ & $10.800 .000,00$ \\
\hline
\end{tabular}

Fonte: Economática e Formulário de Referências.

Após a análise descritiva das remunerações das empresas por tipo de controlador, foi realizado um teste de médias considerando o logaritmo do valor pago a título de remuneração da diretoria.

De acordo com o teste de médias, quando o controlador é familiar, a média de remuneração paga a diretoria ( $\mathrm{R}$ \$ 12.700.000,00 entre os quatro anos) é estatisticamente menor do que quando o controlador é institucional (R\$45.500.000,00) ou quando a 
firma não possui um controlador (RS 16.900.000,00). Já em relação ao controlador governamental (R\$3.668.040,00), não se observou diferença estatística.

Para o controlador institucional, este paga uma remuneração estatisticamente maior do que quando o controlador é familiar ou governamental, e estatisticamente igual quando não existe controlador.

Quando na ausência de controlador, a diretoria recebe estatisticamente mais do que o controle familiar e governamental, e estatisticamente igual ao controle institucional.

Já no controle governamental, os diretores recebem uma menor compensação do que quando o controlador é institucional ou na ausência do mesmo, e igual a quando a firma possui controle familiar.

Dessa forma, a relação entre a remuneração paga aos gestores, de acordo com o teste de médias aplicado ao logaritmo das remunerações é: Controlador Institucional = Ausência de Controlador $>$ Controlador Familiar = Controlador Governamental.

Tabela 6. Resultado do Teste T-Student para Diferença de Médias entre as remunerações dos diferentes tipos de controle. 2010-2013

\begin{tabular}{lcccc}
\hline \multirow{2}{*}{ Tipo de Controle } & \multicolumn{4}{c}{ Resultados do T-Student } \\
\cline { 2 - 5 } & 2013 & 2012 & 2011 & 2010 \\
\hline Familiar x Institucional & $2,8372^{* * *}$ & $3,1671^{* * *}$ & $2,8452^{* * *}$ & $2,7727^{* * *}$ \\
Familiar x Ausência & $2,9316^{* * *}$ & $3,3553^{* * *}$ & $3,3116^{* * *}$ & $2,3180^{* * *}$ \\
Familiar x Governamental & $-0,2163$ & $-0,1684$ & $-0,4977$ & $-0,5655$ \\
Institucional x Ausência & 1,0207 & 1,2543 & 1,4663 & 0,4412 \\
Institucional x Governamental & $-2,3938^{* * *}$ & $-2,5675^{* * *}$ & $-2,6956^{* * *}$ & $-2,7746^{* * *}$ \\
Ausência x Governamental & $-3,6049^{* * *}$ & $-4,4653^{* * *}$ & $-5,5181^{* * *}$ & $-2,6096^{* * *}$ \\
\hline Os valores das remunerações foram considerados em logaritmo. & & \\
Fonte: Economática e Formulário de Referências. & & & \\
$*$ & Estatisticamente significante a 1\%.
\end{tabular}




\subsection{ANÁLISE ECONOMÉTRICA}

4.2.1 Testes de especificação do modelo de dados em painel

Para a escolha adequada do modelo de dados em painel que foi utilizado, foi feito o teste de Breusch-Pagan, o qual a hipótese nula é de que o modelo mais adequado é pooled e a hipótese alternativa é de que o modelo mais adequado é o de efeitos fixos (FE) ou efeito aleatório (RE). Os resultados indicaram que o modelo de efeitos fixos ou aleatório é o mais adequado. Então, foi aplicado o teste de Hausman para definir, entre os dois modelos, qual será o aplicado nas equações. Os resultados do teste Hausman estão em parênteses nas tabelas 7, 8 e 9.

\subsubsection{Resultados das estimações dos modelos de dados em painel}

Para verificar as determinantes da remuneração em cada tipo de controlador foi estimado o modelo 1 (descrito na metodologia). A tabela 7 traz os resultados das quatro equações referentes ao tipo de controlador e seus determinantes para a remuneração.

Tabela 7 - Resultado das estimações do modelo 1 que tem o objetivo de verificar os determinantes da remuneração de acordo com o tipo de controlador. 2010-2013

\begin{tabular}{|c|c|c|c|c|}
\hline Variáveis & $\begin{array}{c}\text { Controle } \\
\text { Familiar } \\
(1)\end{array}$ & $\begin{array}{c}\text { Controle } \\
\text { Institucional } \\
(2)\end{array}$ & $\begin{array}{c}\text { Ausência de } \\
\text { Controlador } \\
\text { (3) }\end{array}$ & $\begin{array}{c}\text { Controle } \\
\text { Governamental } \\
(4)\end{array}$ \\
\hline Tamanho & $\begin{array}{c}0,502^{* * *} \\
(0,078)\end{array}$ & $\begin{array}{c}0,413^{* * *} \\
(0,081)\end{array}$ & $\begin{array}{c}0,565 \\
(0,379)\end{array}$ & $\begin{array}{c}0,427 \\
(0,318)\end{array}$ \\
\hline ROA & $\begin{array}{l}-0,046 \\
(0,132)\end{array}$ & $\begin{array}{c}0,155 \\
(0,124)\end{array}$ & $\begin{array}{c}0,422 \\
(0,785)\end{array}$ & $\begin{array}{l}-3,049 \\
(1,918)\end{array}$ \\
\hline Concentração acionária & $\begin{array}{c}0,000 \\
(0,003)\end{array}$ & $\begin{array}{c}0,002 \\
(0,003)\end{array}$ & $\begin{array}{l}-0,011 \\
(0,011)\end{array}$ & $\begin{array}{l}-0,014 \\
(0,034)\end{array}$ \\
\hline Chair Duality & $\begin{array}{c}-0,376^{* *} \\
(0,150)\end{array}$ & $\begin{array}{c}0,172 * * \\
(0,087)\end{array}$ & $\begin{array}{c}2,220 \\
(1,677)\end{array}$ & $\begin{array}{c}0,451 \\
(0,446)\end{array}$ \\
\hline Independência do conselho & $\begin{array}{l}-0,123 \\
(0,247)\end{array}$ & $\begin{array}{l}-0,300 \\
(0,320)\end{array}$ & $\begin{array}{l}-0,223 \\
(0,758)\end{array}$ & $\begin{array}{c}0,414 \\
(0,599)\end{array}$ \\
\hline Constante & $\begin{array}{c}8,126 * * * \\
(1,163)\end{array}$ & $\begin{array}{c}9.340 * * * \\
(1,295)\end{array}$ & $\begin{array}{c}7,622 \\
(5,621)\end{array}$ & $\begin{array}{c}9,129 \\
(5,511)\end{array}$ \\
\hline Observações & 502 & 227 & 99 & 68 \\
\hline Número de empresas & 128 & 59 & 27 & 17 \\
\hline Estimador & $\operatorname{RE}(0,390)$ & RE $(0,684)$ & FE $(0,002)$ & FE $(0,014)$ \\
\hline
\end{tabular}


Para a equação 1 , as empresas que possuem controle familiar remuneram sua diretoria de acordo com o tamanho, relação já estabelecida na literatura e evidenciada empiricamente de que, quanto maior a empresa, maior a responsabilidade do agente, maior o risco, e com isso, maior a remuneração como apontado por Duffhues e Kabir (2008), Fernandes (2008), Cao et al. (2008), Baber et al. (1996), Firth et al. (2007) e Krauter e Souza (2009).

Nas firmas onde o CEO ocupa também a posição de presidente do conselho de administração, a remuneração da diretoria é menor. Esta relação é contrária a teoria de que o administrador nessa situação teria como estipular uma remuneração maior do que a remuneração eficiente, porém, uma justificativa para essa relação negativa é a de que em firmas familiares essa acumulação de cargos se dá simplesmente para diminuir os custos. Nesse caso, o CEO irá extrair valor não através da sua remuneração, mas sim por meio do uso de bens e fluxos de caixa que estão em nome da empresa em seu benefício. (CAVALLUZZO; SANKARAGURUSWAMY, 2000).

Na equação 2, para as firmas que possuem controle institucional, o tamanho se mostrou significante a $1 \%$ e com coeficiente positivo, evidenciando a relação positiva onde quanto maior a empresa, maior a remuneração, já estabelecida na literatura (CLAY, 2000; HARTZELL; STARKS, 2003; KHAN et al., 2005). A variável da dualidade do CEO exibiu significância a 1\% e coeficiente positivo, indicando que ao presidente da empresa ocupar também a função de presidente do conselho de administração, é possível que ele exerça influência e consiga aumentar sua remuneração acima de um valor de mercado.

Para empresas que não possuem controlador ou empresas de controle governamental, respectivamente, cujos resultados estão nas equações 3 e 4, nenhuma das variáveis se mostrou significante. Dessa forma, impossibilitando alguma inferência sobre os determinantes da remuneração nas empresas que possuem esses controladores.

A tabela 8 traz o resultado das estimações do modelo 2 (vide metodologia), onde o objetivo foi verificar a influência de cada controlador na remuneração em relação aos outros tipos de controle. 
Tabela 8 - Resultado das estimações do modelo 2 para verificar as diferenças entre os controladores na sua influência sobre a remuneração dos executivos. 2010-2013

\begin{tabular}{|c|c|c|c|c|c|}
\hline Variáveis & $\begin{array}{c}\text { Controle } \\
\text { Familiar } \\
(5) \\
\end{array}$ & $\begin{array}{c}\text { Controle } \\
\text { Institucional } \\
(6) \\
\end{array}$ & $\begin{array}{c}\text { Ausência de } \\
\text { Controlador } \\
(7)\end{array}$ & $\begin{array}{c}\text { Controle } \\
\text { Governamental } \\
(8) \\
\end{array}$ & $\begin{array}{c}\text { Modelo } \\
\text { Completo } \\
(9) \\
\end{array}$ \\
\hline Tamanho & $\begin{array}{l}0,440 * * * \\
(0,052)\end{array}$ & $\begin{array}{c}0,457 * * * \\
(0,099)\end{array}$ & $\begin{array}{c}0,456 * * * \\
(0,050)\end{array}$ & $\begin{array}{c}0,454^{* * *} \\
(0,099)\end{array}$ & $\begin{array}{c}0,470^{* * *} \\
(0,050)\end{array}$ \\
\hline ROA & $\begin{array}{c}0071 \\
(0,112)\end{array}$ & $\begin{array}{c}-0,002 \\
(0,121)\end{array}$ & $\begin{array}{c}0,044 \\
(0,104)\end{array}$ & $\begin{array}{c}0,010 \\
(0,124)\end{array}$ & $\begin{array}{c}0,052 \\
(0,109)\end{array}$ \\
\hline Concentração acionária & $\begin{array}{l}-0,004^{*} \\
(0,002)\end{array}$ & $\begin{array}{l}-0.003 \\
(0,002)\end{array}$ & $\begin{array}{c}-0,002 \\
(0,002)\end{array}$ & $\begin{array}{l}-0.003 \\
(0,003)\end{array}$ & $\begin{array}{l}-0,002 \\
(0,002)\end{array}$ \\
\hline Chair Duality & $\begin{array}{c}0,039 \\
(0,230)\end{array}$ & $\begin{array}{c}0,122 \\
(0,317)\end{array}$ & $\begin{array}{c}0,039 \\
(0,229)\end{array}$ & $\begin{array}{c}0,117 \\
(0,315)\end{array}$ & $\begin{array}{c}0,002 \\
(0,229)\end{array}$ \\
\hline $\begin{array}{l}\text { Independência do } \\
\text { conselho }\end{array}$ & $\begin{array}{l}-0,020 \\
(0,199)\end{array}$ & $\begin{array}{l}-0,223 \\
(0,215)\end{array}$ & $\begin{array}{c}-0,084 \\
(0,198)\end{array}$ & $\begin{array}{l}-0,214 \\
(0,213)\end{array}$ & $\begin{array}{l}-0,096 \\
(0,197)\end{array}$ \\
\hline Controle Familiar & $\begin{array}{l}-0,235^{*} \\
(0,142)\end{array}$ & & & & $\begin{array}{c}1,053 * * * \\
(0,230)\end{array}$ \\
\hline Controle institucional & & $\begin{array}{l}-0,163 \\
(0,266)\end{array}$ & & & $\begin{array}{c}1,319 * * * \\
(0,227)\end{array}$ \\
\hline Ausência de controlador & & & $\begin{array}{c}0,593^{* *} \\
(0,250)\end{array}$ & & $\begin{array}{c}1,757 * * * \\
(0,308)\end{array}$ \\
\hline Controle do Governo & & & & $\begin{array}{c}-1,709^{* * *} \\
(0,471)\end{array}$ & \\
\hline Constante & $\begin{array}{c}9,333^{* * *} \\
(0,818)\end{array}$ & $\begin{array}{c}8,906^{* * *} \\
(1,491)\end{array}$ & $\begin{array}{c}8,803^{* * *} \\
(0,786)\end{array}$ & $\begin{array}{c}8,927 * * * \\
(1,491)\end{array}$ & $\begin{array}{c}7,515^{* * *} \\
(0,845)\end{array}$ \\
\hline Observações & 896 & 896 & 896 & 896 & 896 \\
\hline Número de empresas & 224 & 224 & 224 & 224 & 224 \\
\hline Estimador & FE $(0,063)$ & FE $(0,009)$ & $\operatorname{RE}(0,122)$ & FE $(0,017)$ & $\operatorname{RE}(0,145)$ \\
\hline
\end{tabular}

Fonte: Elaboração própria a partir de dados do Formulário de Referências e Economática. Notas: Desvios padrão robustos entre parênteses. *** Estatisticamente significante a 1\%. ** Estatisticamente significante a 5\%. * Estatisticamente significante a 10\%. FE significa Efeitos Fixos e RE significa Efeitos aleatórios. O resultado do teste de Hausman está em parênteses após a indicação do estimador utilizado.

Para todos os tipos de controlador, nas quatro equações $(5,6,7,8)$, o tamanho da empresa se mostrou significante a 1\% evidenciando também um coeficiente positivo, em linha com a hipótese de que firmas maiores tendem a pagar uma remuneração maior a seus diretores, devido ao maior risco, maior responsabilidade e maior exposição, corroborando com as achados na literatura, tais como Firth et al. (2007), Baber et al. (1996), Duffhues e Kabir (2008), Fernandes (2008), Cao et al. (2008), e Krauter e Souza (2009).

Para a equação 5, de controle familiar, a variável concentração acionária se mostrou significante a $10 \%$, e com um coeficiente negativo, sugerindo uma relação inversa, onde, quanto maior a concentração acionária, menor a remuneração paga a sua 
diretoria. Este resultado está de acordo com os trabalhos de Santerre e Neun (1989), Haye (1997), Dyl (1998), Kraft e Niederprum (1999), Firth et al. (2007), John et al., (2010), Kim (2010) e inclusive estudos anteriores no Brasil, como Pinto e Leal (2013), que estudaram a remuneração da diretoria e do conselho de administração quando existem relações familiares dentro do conselho de administração ou entre conselheiros e diretoria. Esse resultado suporta a hipótese de que as famílias têm mais incentivos em utilizar os bens e fluxos de caixas da empresa em benefício próprio somente quando possuem direitos limitados aos fluxos de caixa.

Já o controle familiar foi significante a 10\%, com um sinal negativo, indicando que empresas familiares tendem a remunerar seus executivos com uma quantia menor de divisas do que as outras empresas presentes na amostra. Esse resultado está em desacordo com trabalhos anteriores, como Finkelstein e Hambrick (1989), Haid e Yurtoglu (2006) e Barontini e Bozzi (2011) e alinhado com Cavalluzzo e Sankaraguruswamy (2000), segundo o qual o CEO de firmas familiares extrai valor através de perquisites e não do salário em si, por isso a menor remuneração.

Para a variável controle institucional, na equação 6, não foi possível encontrar evidências de que esta se relacione com a remuneração paga aos diretores de forma mais efetiva. Tal resultado converge com os estudos de Clay (2000) e Hartzell e Starks (2003) e vai de encontro a Khan et al. (2005), onde, mesmo a teoria argumentando de que controladores institucionais possuem mais recursos e mais incentivos para conseguir uma remuneração a nível ótimo, os resultados deste trabalho indicam que na amostra isto não é evidente.

Na equação 7, além do tamanho, a única variável significante foi à ausência de controlador, que com um coeficiente positivo, evidencia uma relação, onde, um controle difuso resulta em uma maior remuneração. Este resultado está em linha com o proposto por Bebchuk e Fried (2005), no qual, o CEO sem controlador consegue definir e auferir uma maior remuneração em comparação a firmas onde existe um controlador, corroborando a hipótese do poder dos gestores, onde, acionistas dispersos e sem incentivos, teriam mais dificuldade para fiscalizar a remuneração da diretoria (BERTRAND; MULLAINATHAN, 2001; PINTO; LEAL, 2013).

Para a equação 8, a variável controle governamental, foi significativa e negativa, alinhada com a hipótese de que as empresas governamentais pagam um valor menor a suas diretorias quando comparado com outros tipos de controlador, porque estes em sua maioria são funcionários públicos (FIRTH et al., 2007; Cao et al., 2007). 
Para a equação 9, relativa ao modelo completo, as variáveis de controle se mostraram significantes. Por meio da análise dos sinais dos coeficientes, é possível estabelecer uma relação entre a magnitude de pagamento conforme o tipo de controlador. As empresas que pagam maior remuneração são aquelas caracterizadas pela ausência de controlador, indicando que nessas empresas o CEO regula sua própria remuneração acima do mercado (BERTRAND; MULLAINATHAN, 2001). Em seguida estão as empresas cujo o controlador é uma instituição, esta teria mais incentivos e mais recursos para remunerar seu administrador de forma ótima (KHAN et al., 2005). Em terceiro estão as empresas de controle familiar, sugerindo que as empresas familiares tendem a remunerar seus executivos com uma quantia menor de divisas do que as outras constantes na amostra. E, por último, as empresas de controle governamental. De acordo com Fan et al. (2011) sua menor remuneração é devida ao fato de as companhias governamentais terem diferentes objetivos, e que os CEO’s geralmente são funcionários públicos com salários fixos ou servidores indicados pelo governo. ${ }^{2}$

Quanto as variáveis de controle do grupo de governança corporativa (chairduality e \% de independência do conselho de administração), das equações 5, 6, 7, 8 e 9, este estudo está de acordo com o estudo nacional de Carvalhal da Silva e Chien (2013), onde não foi encontrada relação entre mecanismos de governança corporativa e remuneração do CEO. Isto, alinhado a medida de desempenho também não se mostrar significante em nenhum modelo, evidencia uma fraca estrutura de governança corporativa, que ao não alinhar a remuneração do CEO ao seu desempenho, perde-se um poderoso incentivo para melhora do desempenho empresarial (FIRTH et al., 2007; DUFFHUES; KABIR, 2008).

\subsubsection{Teste de robustez}

Como teste de robustez, estimou-se o modelo completo em partes (equações 10, 11, 12 e 13) com o objetivo de observar se os coeficientes e a significância das variáveis dos tipos de controlador permanecem constantes a partir da inserção das variáveis de controle. A tabela 9 demonstra os resultados.

Para cada equação estimada foi aplicado o teste Breusch-Pagan que indicou o efeito aleatório ou fixo em relação ao modelo pooled, e também o teste de Hausman que

\footnotetext{
${ }^{2}$ Conclusão respaldada por meio de teste $\mathrm{F}$, com valor $0,012$.
} 
resultou no modelo aleatório para todas as quatro equações. Os resultados do teste de Hausman estão expostos na linha do estimador entre parênteses.

Tabela 9. Resultado da estimação do teste de robustez. 2010-2013

\begin{tabular}{lcccc}
\hline \multicolumn{1}{c}{ Variáveis } & Equação & Equação & Equação & Equação \\
& 10 & 11 & 12 & 13 \\
\hline \multirow{3}{*}{ Tamanho } & & & & \\
& $0,474^{* * *}$ & $0,470^{* * *}$ & $0,466^{* * *}$ & $0,470^{* * *}$ \\
ROA & $(0,047)$ & $(0,049)$ & $(0,049)$ & $(0,050)$ \\
& & 0,054 & 0,057 & 0,052 \\
Concentração acionária & & $(0,114)$ & $(0,115)$ & $(0,109)$ \\
& & & $-0,002$ & $-0,002$ \\
ChairDuality & & & $(0,002)$ & $(0,002)$ \\
& & & 0,002 \\
Independência do conselho & & & & $(0,229)$ \\
& & & & $-0,096$ \\
Controle Familiar & $1,085^{* * *}$ & $1,074^{* * *}$ & $1,043^{* * *}$ & $1,053^{* * *}$ \\
& $(0,209)$ & $(0,208)$ & $(0,211)$ & $(0,230)$ \\
Controle Institucional & $1,336^{* * *}$ & $1,338^{* * *}$ & $1,310^{* * *}$ & $1,319^{* * *}$ \\
& $(0,201)$ & $(0,199)$ & $(0,204)$ & $(0,227)$ \\
Ausência de Controlador & $1,811^{* * *}$ & $1,807^{* * *}$ & $1,731^{* * *}$ & $1,757 * * *$ \\
& $(0,267)$ & $(0,266)$ & $(0,285)$ & $(0,308)$ \\
Constante & $7,271^{* * *}$ & $7,340^{* * *}$ & $7,569^{* * *}$ & $7,515^{* * *}$ \\
& $(0,775)$ & $(0,796)$ & $(0,828)$ & $(0,845)$ \\
Observações & & & & \\
Número de empresas & 896 & 896 & 896 & 896 \\
Estimador & 224 & 224 & 224 & 224 \\
\hline
\end{tabular}

Fonte: Elaboração própria a partir de dados do Formulário de Referências e Economática. Notas: Desvios padrão robustos entre parênteses. ${ }^{* * *}$ Estatisticamente significante a $1 \%$. ${ }^{* *}$ Estatisticamente significante a 5\%. * Estatisticamente significante a 10\%. FE significa Efeitos Fixos e RE significa Efeitos aleatórios. O resultado do teste de Hausman está em parênteses após a indicação do estimador utilizado.

Primeiramente foi estimada a equação 10, controlada pelo tamanho e tipos de controlador, observando-se a significância de todas as variáveis. Posteriormente foi adicionada à equação 10, o ROA, e essa variável, como nos modelos anteriores, não demonstrou relação significativa estatisticamente, enquanto os tipos de controle e o tamanho permaneceram significantes e com o sinal dos coeficientes positivos. $\mathrm{Na}$ equação 12 foi adicionada a concentração acionária, que não se mostrou significante, e os coeficientes e significância do tamanho e dos controles permaneceram basicamente inalterados. Por fim, na equação 13, foram adicionadas as variáveis de governança corporativa (ChairDuality e \% da independência do conselho de administração). 
Novamente estas variáveis não apresentaram significância estatística e as suas inclusões não provocaram alterações significativas nos coeficientes de tamanho e tipo de controle.

De forma conclusiva, não se observou variações significativas nos coeficientes das variáveis do tipo de controlador, mesmo após a adição de cada grupo de variáveis de controle propostas pela literatura. Portanto, o teste de robustez ratifica os principais resultados encontrados na análise anterior. 


\section{CONSIDERAÇÕES FINAIS}

A presente dissertação teve o objetivo de investigar como os diferentes tipos de controlador influenciam na remuneração dos executivos, dentro do mercado brasileiro de capitais, no período de 2010 a 2013, com uma amostra de 224 empresas que negociam seus títulos na BM\&FBOVESPA.

Esse estudo se diferenciou dos anteriores ao introduzir o perfil do controlador como variável explicativa na remuneração da diretoria executiva no ambiente brasileiro, explorando uma lacuna existente na literatura acadêmica acerca desse tema.

A análise demonstrou que a amostra se caracteriza por 56\% das empresas sendo controladas por famílias, $25 \%$ sendo controladas por instituições, $11 \%$ sem controlador e $8 \%$ controladas ao governo, demonstrando que a grande maioria das empresas abertas no Brasil ainda são majoritariamente familiares. Além disso, observou-se alta concentração de capital, já que o capital médio detido pelos 5 maiores acionistas gira em torno de $65 \%$.

Exposto isso, por meio do uso da metodologia de regressão com os dados em painel, buscou-se encontrar os fatores determinantes para a remuneração de acordo com o tipo de controlador da empresa: Controle Familiar, Controle Institucional, Ausência de Controlador e Controle Governamental.

Para as firmas familiares encontrou-se evidências de que estas se relacionam diretamente com o tamanho, ou seja, quanto maior a empresa, maior a remuneração, e inversamente proporcional ao chairduality, no qual, as firmas em que o CEO ocupa também o cargo de presidente do conselho de administração, a remuneração é menor. A explicação para esse fato talvez possa ser a falta de recursos em que empresas familiares de menor tamanho têm em remunerar adequadamente um profissional para ocupar a posição de presidente do conselho de administração. Quanto às firmas de controle institucional, o tamanho também se mostrou uma variável significante para o aumento da remuneração do CEO. Para as empresas sem controlador ou de controle governamental, nenhuma variável do modelo se mostrou significante, impossibilitando a inferência dos determinantes da remuneração nesses dois modelos.

O fato da variável de desempenho ou do vetor de governança corporativa não ser significante na maioria dos modelos é um indicativo de fraca governança e fracos planos de remuneração no Brasil. Dessa forma, a remuneração do gestor não parece estar alinhada com o desempenho da empresa, assim como as medidas de governança 
corporativa também não estão evitando remunerações acima do valor considerado "eficiente".

Após a análise das determinantes, foram estimados outros modelos de regressão com dados em painel, com o objetivo de verificar a influência de cada controlador na remuneração dos seus gestores.

Os resultados indicaram que: 1. As empresas de controle familiar remuneram seus gestores com um valor menor, quando comparadas a empresas com os outros tipos de controle. Este resultado pode ser um indicativo de que o controlador familiar não expropria recursos através da remuneração do gestor, e sim através dos perquisites em nome da empresa; 2. Para as empresas de controle institucional não foi possível fazer inferência acerca da influência do controlador; 3. Quanto as empresas sem controlador, estas remuneram o seu gestor com um valor maior de remuneração, quando comparado com as outras empresas da amostra. Este resultado está em linha com a hipótese de que no caso de o gestor não ter um controlador, ele tende a manipular sua própria remuneração e colocá-la num nível acima do mercado; 4. Assim como as firmas familiares, as empresas de controle governamental, também remuneram com um valor inferior em relação as outras empresas da amostra. Isto já era esperado devido ao fato dos gestores em firmas governamentais serem funcionários públicos e estarem sujeitos a limitações de salário.

No referente a magnitude das remunerações dos gestores, os resultados indicaram que os diretores de empresas que não possuem controlador são os que mais recebem remuneração, seguidos do controle institucional, controle familiar e por último o controle governamental. Este resultado também foi corroborado pelo teste de robustez, onde, o modelo completo foi estimado por partes para verificar sua consistência.

Como sugestão para estudos futuros, recomenda-se utilizar outras variáveis de mensuração de desempenho, como variáveis de mercado, além da separação entre remuneração fixa e variável. Ademais, seria importante um estudo temporal e descritivo mais aprofundado acerca do controle acionário no Brasil. 


\section{REFERÊNCIAS BIBLIOGRÁFICAS}

ATTAWAY, M. C. A study of the relationship between company performance and CEO compensation. American Business Review, v. 18, n. 1, p, 77-85. 2000.

AGGARWAL, R. K; SAMWICK, A. A. Executive compensation, strategic competition, and relative performance evaluation: Theory and evidence. The Journal of Finance, v. 59, n. 6, p. 1999-2043, 1999.

BARONTINI, R.; BOZZI, S. Board compensation and ownership structure: empirical evidence for Italian listed companies. Journal of Management and Governance, v. 15, n. 1, p. 59-89, 2011.

BABER, W; JANAKIRAMAN, S; KANG, S. Investment opportunities and the structure of executive compensation. Journal of Accounting and Economics, v. 21, p. 297-318, 1996.

BATHALA, C.T. Determinants of managerial stock ownership: the case of CEOs. Finance Review, v. 31, n. 1, p.127-47, 1996.

BEBCHUK, L. A.; FRIED, J. M. Executive compensation as an agency problem. Journal of Economic Perspectives, v, 17, p. 71-92, 2005.

BEBCHUK L. A.; FRIED J.M.; WALKER, D. Managerial Power and Rent Extraction in the Design of Executive Compensation. University of Chicago Law Review, v. 69, p. 751- 846, 2002.

BERLE, A.; MEANS, G. The modern corporation and private property. New York: Macmillan, 1932.

BERTRAND, M.; MULLAINATHAN, S. Are CEOs rewarded for luck? The ones without principals are. Quarterly Journal of Economics, v. 116, p. 901-932. 2001.

BM\&FBOVESPA. Ofertas Públicas de Distribuição de Ações. Disponível em: < http://www.bmfbovespa.com.br/pt-br/mercados/acoes/ofertas-publicas/ofertaspublicas.aspx?idioma=pt-br >. Acesso em: 05 de Janeiro de 2014.

BURKART, M.; PANUNZI, F.; SHLEIFER, A. Family firms. Journal of Finance, v. 58, n. 5, p. 2173-2207, 2003.

CAVALLUZZO, K.; SANKARAGURUSWAMY, S. Pay-to-accounting performance and ownership structure in privately-held small corporations. Working paper, 2000.

CAO, J.; PAN, X.; TIAN, G. Disproportional ownership structure and pay-performance relationship: Evidence from China's listed firms. Journal of Corporate Finance, v. 17, p. 541-554, 2011.

CASSON, M. The economics of the family firm. Scandinavian Economic History Review, v. 47, n. 1, p. 10-23. 1999.

CARVALHAL DA SILVA, A. L.; CHIEN, A. C. Y. Remuneração executive, valor e desempenho das empresas brasileiras listadas. Revista Brasileira de Finanças (Online), v. 11, p. 481-502, 2013.

CARLETON, W.T.; NELSON, J.M,; WEISBACH, M.S. The influence of institutions on corporate governance through private negotiations: evidence from TIAA-CREF. J. Finances, v. 53 n. 4, p. 1335- 62, 1998.

CHEN, C.J.P..; LI, Z.; S., X. Sun, Z. Rent-seeking incentives, corporate political connections, and the control structure of private firms: Chinese evidence. J. Corp. Finance, v. 17, n. 2, p. 229-243. 2011.

COHEN, S.; LAUTERBACH, B. Differences in Pay between Owner and Non-owner CEOs: Evidence from Israel. Journal of Multinational Financial Management, v. 18, 2008. 
CLAY, D. The effects of institutional investment on CEO compensation. University of Southern California. working paper, 2000.

CLARKE, D. C. Corporate governance in China: an overview. China Economic Review, v. 14, n. 4, p. 494-507, 2003.

CORBETTA, G.; SALVATO, C. Self-serving or self-actualizing? Models of man and agency costs in different types of family firms: a commentary on "comparing the agency costs of 19 family and non-family firms: conceptual issues and exploratory evidence. Entrepreneurship Theory and Practice, v. 28, n. 4, p. 335-354, 2004.

CHEUNG, Y. L.; STOURAITIS, A.; WONG, A. Ownership concentration and executive compensation in closely held firms: Evidence from Hong Kong. Journal of Empirical Finance, v,12, p. 511-532, 2005.

CORE, J.E.; HOLTHAUSEN, R.H.; LARCKER, D.F. Corporate governance, chief executive officer compensation and firm performance. Journal of Financial Economics, v. 51, p. 371-406, 1999.

COFFEE, J. Liquidity versus control: The institutional investor as corporate monitor. Columbia Law Review, v. 91, p. 1277-1368, 1991.

CUBBIN, J.; LEECH, D. The effects of shareholding dispersion on the degree of control in British companies: theory and measurement. Economic Journal, v. 93 p. 351-69, 1983.

CYERT, R. M.; SOK-HYON, K; KUMAR, P. Corporate Governance,Takeovers, and Top-Management Compensation: Theory and Evidence. Management Science, v. 48, n. 4, p. 453-469, 2002.

DAVID, P; KOCHHAR, R. Barriers to effective governance by institutional investors: implications for theory and practice. Europe Management Journal, v. 14, p. 45766, 1996.

DAVIS, J. H.; SCHOORMAN, F. D.; DONALDSON, L., Toward a stewardship theory of management. Academy of Management Review, v. 22, n. 1, p. 20-47, 1997.

DEVERS, C. E.; CANNELLA JR, A. A.; REILLY, G. P.; YODER, M. E. Executive Compensation: A Multidisciplinary Review of Recent Developments, Journal of Management, v. 33, n. 6, p. 1016 - 1072, 2007.

DIKOLLI, S.; VAYSMAN, I. Contracting on the stock price and forward-looking performance. European Accounting Review, v. 15, n. 4, p. 445-464, 2006.

DUFFHUES, P.; KABIR, R. Is the pay-performance relationship always positive? Evidence from the Netherlands. Journal of Multinational Financial Management, v. 18, p. 45-60, 2008.

DYER, W. G.; WHETTEN, D. A. Family firms and social responsibility: preliminary evidence from the S\&P 500. Entrepreneurship Theory and Practice, v. 30, n. 6, p. 785-802, 2006.

DYL, E. A. Corporate Control and Management Compensation: Evidence on the Agency Problem. Managerial and Decision Economics, v. 9, n. 1, p. 21-25, 1988.

EATON, J.; ROSE, H. S. Agency, delayed compensation, and the structure of executive remuneration. The Journal of Finance, v. 38, n. 5, p. 1489-1505, 1983.

EISENHARDT, K. Agency theory: an assessment and review. Academic Management Review, v. 14, p. 57- 74, 1989.

FAN, J. P. H.; WEI, K. C. J.; XU, X. Z. Corporate finance and governance in emerging markets: a selective review and an agenda for future research. J. Corp. Finance, 2011.

FAHLENBRACH, R. Shareholder Rights, Boards, and Executive Compensation, Review of Finance, v. 13, p. 81-113, 2009. 
FINKELSTEIN, S.; D.C. HAMBRICK, Top management team tenure and organizational outcomes: The moderating role of managerial discretion, Administrative Science Quarterly, v. 35, p. 484-503. 1990.

FERNANDES, N. EC. Board compensation and firm performance: the role of "independent" board members. Journal of Multinational Financial Management, v. 18, p. 30-44, 2008.

FIRTH, M.; FUNG, P.; RUI, O. How ownership and corporate governance influence chief executive pay in China's listed firms. Journal of Business Research, v. 60, p. 776-785, 2007.

GOYAL, V. K.; PARK, C. W. Board leadership structure and CEO turnover, Journal of Corporate Finance, v. 8, p. 49-66, 2002.

HARTZELL J.C, STARKS L.T. Institutional investors and executive compensation. AFA Washington (DC): Meetings, 2003.

HAID, A.; YURTOGLU, B. B. Ownership structure and executive compensation in Germany. SSRN, New York, Dec., 2006. Disponível em: $<$ http://ssrn.com/abstract=948926>. Acesso em: $12 \mathrm{dez} .2014$.

HAYE, E. Corporate control effects and managerial remuneration in commercial banking. Journal of Economics and Business, v. 49, p. 239-252, 1997.

JAMES, H. S. Owner as manager, extended horizons and the family firm. International Journal of the Economics of Business, v. 6, n. 1, p. 41-55. 1999.

JENSEN, M; MECKLING, W. Theory of the firm: Managerial behavior, agency costs and ownership structure. Journal of Financial Economics, v. 3, n. 4, p. 305-360, 1976.

JENSEN, M; MURPHY, K. Performance Pay and Top Management Incentives. Journal of Political Economy, v. 98, p. 225-264, 1990. CEO bonus plans: and how to fix them. Working paper, 2011.

JENSEN, M; MURPHY, K; WRUCK; E. Remuneration: Where we've been, how we got to here, what are the problems, and how to fix them. Working paper, 2004.

JOHN, K.; MEHRAN, H.; QIAN, Y. M. Outside monitoring and CEO compensation in the banking industry. J. Corp. Finance, v. 16, n. 4, p. 383-399. 2010.

JOHNSON, S.; LA PORTA, R.; LOPEZ-DE-SILANES, F.; SHLEIFER, A. Tunneling. Am. Econ. Rev., v. 90 n. 2, p. 22-27, 2000.

KHAN, H.; DHARWADKAR, R.; BRANDES, P. Institutional ownership and CEO compensation: a longitudinal examination. Journal of Business Research, v. 58, p, 1978-1088, 2005.

KATO, T; KUBO, K. CEO compensation and firm performance in Japan: Evidence from new panel data on individual CEO pay. Journal of the Japanese and International Economies, v. 20, p. 1-19, 2006.

KATO, T.; LONG, C. Executive compensation, firm performance and corporate governance in China: evidence from firms listed in the Shanghai and Shenzhen Stock Exchange. Econ. Dev. Cult. Change, v. 54, n. 4, p. 39-81, 2005.

KRAFT, K; NIEDERPRUM, A. Determinants of management compensation with riskaverse agents and dispersed ownership of the firm. Journal of Economic Behavior \& Organization, v. 40, p. 17-27, 1999.

KRAUTER, E.; SOUSA, A. F. The Relationship between Executive Remuneration and Corporate Financial Performance in Brazil. International Journal of Business Research, v. 9, p. 138-151, 2009.

KE, B.; PETRONI, K.; SAFIEDDINE, A. Ownership concentration and sensitivity of executive pay to accounting performance measures: evidence from publicly and privately-held insurance companies. J. Acc. Econ, v. 28, n. 2, 185-209. 1999. 
KIM, K. Blockholder monitoring and the efficiency of pay-performance benchmarking. J. Corp. Finance, v. 16, n. 5, p. 748-766. 2010.

LA PORTA. R.; LOPEZ-DE-SILANES. F.; SHLEIFER. A. Corporate ownership around the world, Journal of Finance, v. 54, p. 471-518. 1999.

LEE, J. Executive performance-based remuneration, performance change and board structures. The International Journal of Accounting, v. 44, p. 138-162, 2009.

MEHRAN, H. Executive compensation structure, ownership, and firm performance. Journal of Financial Economics, v. 38, p. 163-184, 1995.

MISHRA, C; MCCONAUGHY, D; GOBELI, D. Effectiveness of CEO pay-forperformance. Review of Financial Economics, v. 9, p. 1-13, 2000.

MORCK, R.; SHLEIFER, A.; VISHNY, R. W. Management ownership and market valuation: an empirical analysis. Journal of Financial Economics, v. 20, p. 293315, 1988.

MORCK, R; YEUNG, B. Agency problems in large family business groups.

Entrepreneurship Theory \& Practice, v. 27, n. 4, p. 367-382. 2003.

MORCK, R. Behavioral finance in corporate governance: economics and ethics of the devil's advocate. Journal of Management Governance, v. 12, p. 179-200, 2008.

MURPHY, K. Executive Compensation. Handbook of labor economics, v. 3, p. 24852563, 1999.

NIAP, D; TAYLOR, D. CEO personal reputation: does it affect remuneration during times of economic turbulence? Procedia Economics and Finance, v. 2, p. 125134, 2012.

PINTO, M. B.; LEAL, R. P. C. Ownership Concentration, Top Management and Board Compensation. RAC. Revista de Administração Contemporânea (Online), v. 17, p. 304-324, 2013.

ROSEN, S. Contracts and the market for executives. Basil Blackwell, Oxford, 1992.

ROSS, S. The economic theory of agency: The principal's problem. American Economic Association, p. 134-139, 1973.

SANTERRE, R. E.; NEUN, S. P. Dispersion and dispersion compensation. The Review of Economics and Statistics, v. 68, n. 4, p. 147-197, 1986.

SLIWKA, D. On the use of nonfinancial performance measures in management compensation. Journal of Economics \& Management Strategy, v. 11, n. 3, p. 487-511, 2002.

SHLEIFER, A; VISHNY, R.W., A survey of corporate governance. Journal of Finance, v. 52, n. 2, p. 737-783, 1997.

STERNBERG, L.; LEAL, R. P. C.; BORTOLON, P. M. Affinities and agreements among Brazilian shareholders. International Journal of Disclosure and Governance, v. 8, n. 3, p. 213-228, 2011.

TOSI, H; WERNER, S; KATZ, J; GOMEZ-MEJIA, L. How much does performance matter? A meta-analysis of CEO pay studies. Journal of Management, v. 26, n. 2, p. 301-339, 2000.

TOSI, H; MISANGYI, V; FANELLI, A; WALDMAN, D; YAMMARINO, F. CEO charisma, compensation, and firm performance. The Leadership Quartely, v. 3, p. 405-420, 2004.

YERMACK, D. Do corporations award CEO stock options effectively? Journal of Financial Economics, v. 39, p. 237-269, 1995.

. Higher market valuation for firms with a small board of directors. Journal of

Financial Economics, v. 40, p. 185-211, 1996. 
ZAKARIA, I. Performance measures, benchmarks and targets in executive remuneration contracts of UK firms. The British Accounting Review, v. 44, p. 189-203, 2012.

ZHOU, X. CEO pay, firm size, and corporate performance: Evidence from Canada. Canadian Journal of Economics, v. 33, p. 213-251, 2000. 